IZA DP No. 8129

The Productivity of Working Hours

John Pencavel

April 2014 


\title{
The Productivity of Working Hours
}

\author{
John Pencavel \\ Stanford University \\ and IZA
}

\section{Discussion Paper No. 8129 \\ April 2014}

IZA

\author{
P.O. Box 7240 \\ 53072 Bonn \\ Germany
}

\author{
Phone: +49-228-3894-0 \\ Fax: +49-228-3894-180 \\ E-mail: iza@iza.org
}

\begin{abstract}
Any opinions expressed here are those of the author(s) and not those of IZA. Research published in this series may include views on policy, but the institute itself takes no institutional policy positions. The IZA research network is committed to the IZA Guiding Principles of Research Integrity.

The Institute for the Study of Labor (IZA) in Bonn is a local and virtual international research center and a place of communication between science, politics and business. IZA is an independent nonprofit organization supported by Deutsche Post Foundation. The center is associated with the University of Bonn and offers a stimulating research environment through its international network, workshops and conferences, data service, project support, research visits and doctoral program. IZA engages in (i) original and internationally competitive research in all fields of labor economics, (ii) development of policy concepts, and (iii) dissemination of research results and concepts to the interested public.
\end{abstract}

IZA Discussion Papers often represent preliminary work and are circulated to encourage discussion. Citation of such a paper should account for its provisional character. A revised version may be available directly from the author. 
IZA Discussion Paper No. 8129

April 2014

\section{ABSTRACT}

\section{The Productivity of Working Hours}

Observations on munition workers, most of them women, are organized to examine the relationship between their output and their working hours. The relationship is nonlinear: below an hours threshold, output is proportional to hours; above a threshold, output rises at a decreasing rate as hours increase. Implications of these results for the estimation of labor supply functions are taken up. The findings also link up with current research on the effects of long working hours on accidents and injuries.

JEL Classification: J24, J22, N34

Keywords: working hours, output, productivity, women workers

Corresponding author:

John Pencavel

Department of Economics

Stanford University

Stanford, CA 94305-6072

USA

E-mail: pencavel@stanford.edu 


\section{THE PRODUCTIVITY OF WORKING HOURS}

John Pencavel*

\section{Introduction}

In empirical research on measuring the input of labor in production, hours of work are treated in different ways. One approach is to neglect work hours entirely and to measure the input of labor by the number of employed workers. Another practice is to use worker-hours, the product of the number of workers and average hours per worker, an approach implying that a given proportionate change in the number of workers has the same effect on the labor input as the same proportionate change in working hours per worker. Either of these two ways of proceeding might be correct although it would seem worthwhile to ascertain whether it is.

As it is, in each recession, calls are made to alleviate unemployment by reducing work hours among the employed. After all, if the labor input is simply the sum total of hours worked by all workers, so the reasoning goes, this sum can be arrived at if each works fewer hours and more people are employed. Indeed, some governments have applied this reasoning and made changes that encourage or mandate work-sharing.

Another line of research recognizes that changes or differences in working hours do not entail the same changes or differences in effective labor input because individuals tend to work with greater efficacy at shorter hours. Economists engaged in growth accounting research took the position that workers employed for fewer hours were more productive during these hours so that gains in output per hour offset, in part, a shorter working week. Thus Denison (1962) suggested that, at the level of working hours in 1929 (when weekly working hours were 49 hours averaged over 52 weeks), a reduction in hours would be fully offset in gains that would leave output unchanged. At the hours prevailing in 1957 (when hours averaged 40 hours), Denison conjectured that a ten percent reduction in hours would result in a six percent reduction in output. ${ }^{1}$

Dension's conjectures build on a long history of case studies in which a few employers have investigated the consequences of cuts in their employees' working hours. These can be traced back at

\footnotetext{
* Research assistance from Shirlee Lichtman is gratefully acknowledged. I profited from conversations with David Card, Avner Greif, and Priya Satia during the preparation of this paper.

${ }^{1}$ Similar arguments are made by Matthews, Feinstein, and Odling-Smee (1982).
} 
least to Robert Owen's cotton mills in New Lanark in the early nineteenth century. A well-known case was that at the Salford Iron Works in 1893 where William Mather cut weekly hours from 53 to 48. Even though most private employers found reasons to doubt his findings ${ }^{2}$, Mather deemed it a success as did some government ministers who instituted a shorter working week in state-managed enterprises including the Woolwich Arsenal Works. In turn, this inspired Ernst Abbé at the Zeiss Optical Works at Jena in Germany to cut the length of the workday from nine to eight hours. During the first few decades of the $20^{\text {th }}$ century, in the United States, the National Industrial Conference Board commissioned a number of studies on the effects of shorter hours. The focus of these and subsequent reviews (such as those of Brown (1965) and Kossoris and Kohler (1947)) was on "before” and "after” comparisons: did output fall after a discrete cut in working hours? The results in this paper are based on more than two observations ("before” and "after”) on hours and suggest that the effect on output of a reduction in hours depends on the initial level of working hours.

In more recent years, economists have estimated aggregate production functions ${ }^{3}$ in which the effects of variations in the number of workers are distinguished from the effects of variations in hours worked per worker. In this paper, the observations on working hours are at the level of the place of work and production. In addition, the values of hours studied below extend over a wider range than typically available. For instance, in Feldstein's (1967) paper on hours and employment in a CobbDouglas production function, working hours in 1960 across 24 industries ranged from 41 to 50 hours per week and the coefficient of variation of hours is 0.076. By contrast, the observations examined in Section IV.A below range from 24 hours to 72.5 hours per week and their coefficient of variation is 0.200 .

A simple organizing framework is to suppose that, if $H_{i}$ is worker $i$ 's hours of work over a period of time and if $E_{i}$ is $i$ 's work effort per hour over that period, then $i$ 's effective labor input, $L_{i}$, may be defined as $L_{i}=E_{i} . H_{i}$, an expression without empirical content, as yet, because $E_{i}$ is unobserved. If $E_{i}$ is simply a constant, $a$, then $L_{i}=a \cdot H_{i}$ and worker $i$ 's effective labor input is

\footnotetext{
2 "The consensus in private industry was against any reduction in working hours and the 48 hour working week did not become the norm in British industry until 25 years later...” (McIvor(1987, p. 728)). Goldmark (1913) provides a good description of some of these early case studies.

${ }^{3}$ The aggregation is usually at the level of industries as in Feldstein (1967), Hart and McGregor (1988), Leslie and Wise (1980), or Marti(2000). Hamermesh (1993) reviews this work.
} 
proportional to his working hours and, if $i$ is typical of workers, a firm's effective labor input is the sum of hours worked over all workers. This would rationalize the use of worker-hours.

More plausibly, $i$ 's work effort depends on his hours of work: $E_{i}=f\left(H_{i}\right)$ where $f\left(H_{i}\right)$ embodies the stress, fatigue, monotony, and stimulation that accompanies work. In this event, the output-hours relation depends on the form of $f\left(H_{i}\right)$. If $f\left(H_{i}\right)=a_{0}+a_{1}$. $H_{i}$ where $a_{0}>0$ and $a_{1}<$ 0 , then $L_{i}=a_{0} \cdot H_{i}+a_{1} \cdot H_{i}{ }^{2}$ and $i$ 's effective labor input rises with hours worked but at a decreasing rate. If $i$ 's effort is a positive quadratic function of hours, then his effective labor input is a cubic function of his hours, which could justify Denison's conjectures. The research reported below may be interpreted as an investigation into the shape of $f\left(H_{i}\right)$.

A shortcoming of the data studied here is the small number of observations: for scholars who have become accustomed to research based upon thousands of data points, the research reviewed here may appear almost anecdotal. Perhaps it is. However, it should be understood that many of the (often unobserved to the researcher) differences among workers in contemporary data sets are small when examining workers in the same workshop doing the same work. Also, whether anecdotal or not, these observations were influential in decisions to reduce working hours.

The evidence in this paper on the effect of working hours on output is drawn from the research undertaken by investigators of the British Health of Munition Workers Committee (HMWC) during the First World War, the Great War. As described below, this Committee was charged with providing the Minister of Munitions with advice regarding the health and efficiency of workers in munition plants and, as part of its investigations, the Committee commissioned studies within munition factories into the link between work hours and work performance. In recent years, there have been several useful reviews of the research conducted within firms, ${ }^{4}$ but this literature has overlooked the earlier work done by the investigators of the HMWC and by the subsequent Industrial Fatigue and Industrial Health Research Boards. This research almost a century ago on the stressful effects of long hours of work is likely to be relevant today for certain workers as reviewed below. First, consider the context of the research conducted by the HMWC investigators.

${ }^{4}$ See Harrison and List (2004) and Bandiera, Barankay, and Rasul (2011). 


\section{The Health of Munition Workers Committee (HMWC)}

\section{A. The Setting}

In 1914, the outbreak of war caused the British government to suspend regulations on work hours in plants producing war-related material. The working week was extended and "the employment of men for 70 to 90 hours a week was common, for over 90 hours was not infrequent, and there were even cases of hours in excess of 100". 5 Sunday work was reintroduced. Even though hours had probably been reduced somewhat since the beginning of 1915, by the first half of 1916, a random survey of over 3,000 men at eight armaments factories still found more than a third aged 41 years and older were working 70 to 100 hours per week while 58 percent of boys aged 18 years and younger were working more than 60 hours per week. A majority of 1,326 women in munition factories were at work more than 60 hours per week. ${ }^{6}$

For almost two years, the military relied on volunteers. ${ }^{7}$ The military called for "men, more men, and still more men” (Herbert Kitchener) and for “munitions, munitions, more munitions” (John French). The voracious demand for young men to serve in the military and the insatiable demand for munitions resulted in a huge demand for workers in the munition plants. This demand for labor was met, principally, by young women working long hours. By the end of the War (December 1918), threequarters (precisely 77.6 percent) of all employees in the Ammunition and Explosives industry were women.

The replacement of younger men by novice workers was not welcomed by some of the older skilled men already employed in the munition plants. Their concern was that this would result in work being divided into a number of smaller operations, each of which required little skill. The workers suspected their control over the entire process would be undermined and, ultimately, their skilled wages would be challenged. This process was known as “dilution”; “deskilling” might be the word used more often today. ${ }^{8}$

\footnotetext{
${ }^{5}$ See the HMWC (1919, para. 122).

${ }^{6}$ These were reported by Agnew (1917) and Campbell and Wilson (1917).

${ }^{7}$ The conscription (draft) of unmarried men aged 18-41 years started in March 1916 and extended to married men in May 1916. In 1918, the age limit on military service was raised to 51 years.

${ }^{8}$ A similar concern was experienced just before and during the Second World War. See Hart (2007).
} 
In response to the doubts expressed about the wisdom of long hours, the newly-formed Ministry of Munitions ${ }^{9}$ established a Health of Munition Workers Committee (HMWC) in September 1915 “to consider and advise on questions of industrial fatigue, hours of labour and other matters affecting the personal health and efficiency of workers in munition factories and workshops”. The Committee took up many issues relating to work activity including the quality of the working environment inside factories such as the food and water available to workers, washing facilities, baths, protective clothing, temperature, ventilation and lighting as well as injuries, accidents, diseases, prolonged standing, and welfare supervision. The HMWC paid special attention to the exposure of these workers to noxious chemicals and gases contained in the shells, components that caused fatalities through poisoning and that resulted in some huge explosions. ${ }^{10}$ Work in munition factories was dangerous and the HMWC recommended steps to protect the workers from harmful elements.

\section{B. Output and Hours}

An important part of their investigation was directed to the arrangement and duration of work including the association between the output of workers and their hours of work, the focus of this paper. The HMWC heard different views on the desirable length of work hours, but they attached significance to the fact that they knew of "no employer who had once adopted the shorter scale of hours ever desires to return to the longer period”. In view of the anecdotal information then dominant, the HMWC recognized the value of collecting systematic and meaningful information on the link between the output of workers and their hours of work. To this end, the HMWC commissioned quantitative investigations into the factors affecting the efficiency with which individuals work in the statecontrolled munition plants.

The HMWC operated for a little over two years and produced 21 Memoranda on activities in munitions plants. Because its findings and recommendations were relevant to workplaces in other industries, shortly after its disestablishment at the end of 1917, a new agency (the Industrial Fatigue

\footnotetext{
${ }^{9}$ The first Minister of Munitions was the energetic David Lloyd George followed by Edwin Samuel Montagu, Christopher Addison, and, finally, Winston Churchill.

10 The shells' ingredients included tetryl, sulphur, mercury, lead, nitric acid and trinitrotoluene, components that turned the workers' skins yellow causing the young women to be known as "canaries". There were massive explosions at munition factories at (among others) Faversham (Kent) in 1916, Silvertown (Essex) in 1917, and Chilwell (Nottinghamshire) in 1918.
} 
Research Board) was formed in July 1918 "To consider and investigate the relations of the hours of labour and of other conditions of employment including methods of work, to the production of fatigue, having regard both to industrial efficiency and to the preservation of health among the workers”. From 1921, this Board became an arm of the Medical Research Council and, in recognition of its broader agenda, in 1928 it was renamed the Industrial Health Research Board. ${ }^{11}$

C. The Recommendations of the HMWC

From the evidence brought to their attention, in January 1916, the HMWC recommended shorter working hours: for men, hours of no more than 65-67 per week (13-14 hours daily) on average and for boys, for girls, and for women a maximum of 60 weekly hours. It is not always clear whether these recommendations referred to scheduled hours or actual hours worked. ${ }^{12}$ The basis for these recommendations was not because shorter hours would yield higher average product or higher marginal product, but because total output would be unchanged. ${ }^{13}$ This is a remarkable claim which is explored below. ${ }^{14}$

In addition to endorsing the value of regular holidays and the benefits of rest pauses, the Committee was particularly critical of work on Sunday. They wrote, "The evidence is conclusive that Sunday labour by depriving the worker of his weekly rest offers him no sufficient opportunity for

11 The Memoranda and Reports of the HMWC received a good deal of attention in the United States and much of the work of the HMWC was reproduced by the U.S. Bureau of Labor Statistics in their Bulletins. The National Industrial Conference Board (1917) published a useful report on the research on the output and hours of munition workers in Britain.

${ }^{12}$ These recommendations were contained in HMWC (1916a). They were accepted by the Home Office which issued a General Order in September 1916 embodying these and other recommendations.

13 Thus, the HMWC's Final Report states, “There can be little doubt......from the investigations of Dr. Vernon and Professor Loveday......that substantial reduction in hours can be effected without any reduction in output.” (1919, p. 38, para. 156). In describing the weekly output and weekly working hours of 100 women engaged in "moderately heavy labour", after observing the output of women working 60 hours a week, Vernon (in HMWC[1916b]) determined that "an equally good total output could be maintained if the actual working hours were reduced to 56 or less per week".

${ }^{14}$ A munition firm's awareness of output was reinforced by “cost plus bonus” contracts that were among those contracts used by the Ministry of Munitions. According to this type of contract, "the contractor received a bonus per unit.......as an encouragement to increased production” Ministry of Munitions (1922, p.23). 
recovering from fatigue, and is not productive of greater output except for quite short and isolated periods......seven days' labour only produces six days’ output and.....reductions in Sunday work have not in fact involved any appreciable loss of output." The findings of Thomas Loveday were quoted: “The effects of Sunday labour are, as has now been recognised, still worse than those of overtime hours in the evening or on Saturday afternoon.”

In its Final Report issued in April 1918, the HMWC modified its earlier recommendations by urging even shorter work hours: “.....the length of hours of employment provisionally recommended two years ago are now too long and can be reduced without loss of output”. ${ }^{15}$ Again, the Committee believed the cut in hours would not result in a fall in output.

\section{Night Work}

Before the War, Britain subscribed to an international convention that prohibited the employment of women on night work. This ban was lifted with the exigencies of war and the HMWC deemed that, given the military's demands for shells and even though it is "unnatural to turn night into day”, night work would be “inevitable” for men and for women throughout the War.

In assessing the relative merits of day work and night work, the HMWC distinguished between continuous and discontinuous shifts. A discontinuous schedule involved alternating between one week (or fortnight) of day work followed by one week (or fortnight) of night work for a given body of workers. The continuous schedule maintains workers on night work without an interval of day work or the schedule keeps workers on day work without a period of night work. Even though the continuous employment of women on night shifts was not frequent in munitions factories, some cases were identified and, according to the Committee, the output of the workers on night shifts was "very unfavourable” compared with the output of day workers. The Committee believed the continuous system of night work denied workers complete sleep and rest which are more difficult to secure during the day. The HMWC took a benign view of night work on the discontinuous system: "There is no significant difference between the rate of output in night and day shifts managed on the discontinuous system. If there be any difference, it would seem that the output is slightly better by night for the

\footnotetext{
${ }^{15}$ The quotes in this and the previous paragraph are from the HMWC's Final Report, page 44, para 194, Section VII of (“Sunday Labour and Night Work”) and page 122 of Section XX.
} 
particular class of work involved." 16

\section{A General Description of the Data Collected by the HMWC's Investigators}

The description of the data in this section applies to all the observations investigated below.

\section{A. Working Hours}

The investigators distinguished between scheduled hours of work and actual hours of work by subtracting from scheduled hours time "lost" to sickness, absence, meal times, interruptions, and time spent in setting up before production and cleaning up after spells of production. "Lost time"through sickness was sometimes attributed to the fatigue following long hours of work. In the analysis below, hours of work refers to actual work hours, not to scheduled hours.

Variations in work hours were due not only to the military's demands for munitions but also to illness, absenteeism, and temporary shortages of raw material. Shorter hours were scheduled around holidays at Christmas, the New Year, Easter, and Whitsun. Most of the observations are drawn from the year 1916, a year in which major military campaigns were waged involving terrific loss of life and extraordinary expenditure of shells. ${ }^{17}$ In the observations on hours below, some of the variation in working hours took the form of working or not working on Sunday. This may have a different effect upon output from variations in hours spread evenly over six days.

\section{B. Output and Earnings}

Most of the workers were paid on a piece-rate basis. Their output formed the basis of their wage payments and allowed the researchers to have a well-defined measure of performance. In some instances, the output measure is simply the number of shells produced, but in cases where the workers were engaged in a particular stage in shell production the investigators report an index number of their output. "The shrill, demented, choirs of wailing shells" and the women (the "canaries") who made

\footnotetext{
${ }^{16}$ These quotations are from "The Comparative Efficiencies of Day Work and Night Work in Munition Factories” contained in the Interim Report of the HMWC (1917), pages 26-40.

${ }^{17}$ Woollacott (1994, p. 67) notes that, "In the buildup before the launching of the Battle of the Somme, the Woman Worker complained that, despite union protests and questions in the House of Commons, the Ministry of Munitions had allowed the Vickers Factory at Erith and a national factory at Huddersfield both to change from eight-hour shifts to twelve-hour ones, and Vickers at Barrow seemed about to do the same. Factory holidays were often postponed or canceled due to the exigencies of War as decided by the Ministry of Munitions.”
} 
them were defining elements of the Great War. ${ }^{18}$

Precise earnings are not provided in the investigators' commentaries, but they are described as affording the workers a relatively high standard of living. ${ }^{19}$ Nominal earnings rose over the War years and "their rates of pay varied more or less with the cost-of-living” (Vernon (1940), p.16).

\section{Restriction of Output}

It is natural to question whether observations during a time of national emergency when individuals were exhorted to work for collective goals can permit valid inferences to be drawn about the behavior of workers in "normal" peace-time conditions. In at least one sense, the unusual conditions of war resulted in a more unconstrained work situation than those prevailing in peace time. Before the Great War, the existence of various restrictions on work in British industry was widely noted especially among piece-rate workers. Often these were inspired by the fear that workers who produce high levels of output - "rate busters" - will cause an employer to believe the piece-rate has been set at an unnecessarily high level and the employer's response would be to cut the rate. To prevent such behavior, workers were prevailed upon to produce below some threshold. Some of these restrictions on output were prompted by trade union activity but, in other cases, they were applied and enforced by unorganized workers. ${ }^{20}$ Differences among workers in the nature and extent of these restrictions would frustrate the process of drawing inferences about the relationship between output and work hours.

The Munitions of War Act of 1915 prohibited all restrictions on output and work rules in munition plants. ${ }^{21}$ In addition to the proscription of output-constraining work rules, the Act banned strikes and lockouts in the munition industry (with disputes resolved through compulsory arbitration),

\footnotetext{
${ }^{18}$ The British Army was said to have fired 170 million shells by the end of the War. The shells and the women appear in poems (such as Wilfred Owen’s ‘Anthem for Doomed Youth’) and in novels referring to the "yellow-skinned women” (Barker (1992)).

19 “......She worked in a factory, she said, making detonators. Twelve-hour shifts, six days a week, but she liked the work, she said, and it was well paid. 'Fifty bob a week.......... I was earning ten bob before the war.' " Barker (1992, p. 89).

20 The HMWC characterized restrictions of output as an "unconscious slackening of effort" that represented "a kind of physiological self-protection" from excessive working hours imposed on workers. See HMWC, Final Report, p. 18, para. 68. Drake (1917, p. 47) expressed a similar judgment.

${ }^{21}$ In the observations on hours analysed below, the investigators state that restrictions on output were absent.
} 
a worker was not permitted to leave a munitions employer for another without the previous employer's permission in the form of a leaving certificate, ${ }^{22}$ and changes in wage rates required the approval of the Ministry of Munitions. These far-reaching provisions were enforced by quasi-judicial tribunals that dealt with appeals relating to their operation. ${ }^{23}$

These features were a radical departure from the "night watchman” role for government that Britain aspired to in peacetime so there is good reason to question whether patterns of behavior exhibited during this War offer lessons relevant to less state-regulated labor markets. The principal concern of this paper - the link between the hours worked by employees and their output - may be affected by the Act's regulations and by the extra effort summoned to defeat the country's enemy although the way in which the relation is affected - if at all - is difficult to determine without recourse to more observations. One may surmise that, during a national emergency, workers might suppress any measured fatigue that would emerge in peacetime.

D. Health

The HMWC not only commissioned research on the link between working hours and output, but also authorized the study of sickness. Physical examinations of many workers were conducted. By collecting data on sickness rates (as documented by medical certificates) from factories from "all parts of the country”, Thomas Loveday (1917) identified a number of empirical regularities associated with work. For example, he determined that work before breakfast ("an inheritance partly from the necessary habits of agriculture”) was both harmful to the worker's health and also relatively unproductive work time. He maintained that "food should precede work". From the sickness rates at different munitions factories, he concluded that "the effect of long hours, much overtime, and especially Sunday labour, upon health is undoubtedly most deleterious”.

This is relevant to the study of the link between working hours and output because it suggests

\footnotetext{
${ }^{22}$ The motivation for such a drastic intrusion into a worker's liberties was to avoid competitive bidding by firms for scarce workers. By contrast, employers were not forbidden to fire a worker. The asymmetry rankled some. The leaving certificates were repealed in October 1917.

${ }^{23}$ Rubin's (1987) study concentrates on the workings of the Act in Glasgow where it was very controversial. A publication of the Fabian Research Department and the Fabian Women's Group (Drake(1917, p.26)) claimed “.....the effect of the Munitions of War Act, 1915, was to reduce the workers to a state bordering on slavery....”.
} 
a possible selection problem: this output-hours association will be measured in the next section for those workers on the job; owing to a greater incidence of sickness, those workers on relatively long work shifts are more likely to be absent from work. In other words, the output-hours relationship will be measured from observations on those workers whose work hours have not caused them to miss work because of sickness and, in this respect, the relationship estimated will be fitted to those workers with greater tolerance of long work hours. In using observations on relatively healthy workers, the impact of long hours on worker fatigue may be understated.

\section{E. Other Factors}

The HMWC investigators were sensitive to the relevance for the performance of the workers of other factors affecting their work such as the organization of the workshop and changes in complementary machinery. In one instance below, observations on hours and output are available for workers operating with two different types of physical capital and this will be recognized in the analysis. In other cases, the absence of changes in production methods and machinery is mentioned. ${ }^{24}$

In most of data analysed below, the number of workers is constant (or, approximately, so) except in one case where the number of individuals at work varies across the shifts and this information will be taken into account. The data collected by the investigators were drawn from the "wage sheets" and other personnel records kept by the factories to determine their workers' wage payments and the employees were unaware that their work was to be examined by researchers. Hence there is no reason to believe the workers altered their behavior because they were the subject of analysis.

\section{Hours and Output}

Now consider some of the data collected by the HMWC researchers on the output of the workers and various dimensions of their hours of work. There are three types of observations on the association between work hours and output. The first is a time-series of 122 weekly observations on the weekly output and average weekly work hours for workers on four jobs that range from "heavy

\footnotetext{
${ }^{24}$ For $4 \frac{1}{2}$ months previously and during the period from which these data are drawn, no changes were made “.....in the tools, the machinery, the nature of the operation or the quality of the alloy used.", HMWC ([1916b]) Turnover caused the composition of the workers to change over this period although the majority of the workers at the beginning were present at the end. The report claimed "in this particular operation, there was no appreciable difference between the output of the old experienced workers and of fresh and comparatively inexperienced workers”.
} 
labour" to "light labour". The second type of observations consists of cross-section observations on the average weekly hours and average weekly output of shells of 43 individual women workers employed at two munition workshops. The third type of observations are diurnal data on hours worked over the day or over the night and the output produced each hour as hours at work increase. There are 77 hourly observations drawn from two workshops. Consider these observations in turn.

A. Observations over Time on Weekly Hours and Output of Four Groups of Workers

The observations described in this section were collected by H.M.Vernon and they describe the average weekly hours of work and weekly output of four groups of workers over approximately a year (1916) in a large factory in the Midlands (Vernon (1940, p.16)): there are 56 weekly observations on about 100 women engaged in “moderately heavy labour”; there are 26 weekly observations on another 40 women engaged in "light labour"; there are 31 weekly observations on 56 men engaged in "heavy labour"; and there are 9 weekly observations on 15 youths aged from 15 to 18 years engaged in "light labour”. ${ }^{25}$ The workers were employed in particular stages in the production of munitions and the output measure is an index number of their weekly output.

Descriptive statistics on weekly work hours and weekly output for each of these groups of workers and for all of these workers pooled together are presented in Table 1. The central tendency of hours is around 51 hours per week although they range from a minimum of 24 hours to a maximum of 72.5 hours. Measures of the dispersion in weekly output are similar for the four groups of workers. In each case, the mean value of weekly output is a little below the median value suggesting a tendency for the distribution of output to be skewed to the left.

A visual impression of the output-hours relation is provided by the scatter diagrams in Figure 1 (on women) and Figure 2 (on men and youths). These data will be used to address the following questions prompted by the recommendations of the HMWC: would a shorter working week have resulted in no loss of output?; are the HMWC's strictures against Sunday work consistent with the

\footnotetext{
25 The task of the 100 women was that of turning fuze bodies, that of the 40 women was milling (grinding) a screw thread, that of the 56 men was sizing fuze bodies, and that of the 15 youths boring top caps. Horace Middleton Vernon (1870-1951) taught physiology at Oxford University. During a vacation in 1915 he worked in a shell factory in Birmingham and, later, volunteered his services to the HMWC. Subsequently he worked for the Industrial Fatigue Research Board. He was described as “.....meticulously careful in his collection of data” (Bedford (1951)). His research on output and hours is contained in Vernon (1921).
} 
output-hours relationship?

To take up these questions, initially, the four groups of workers were analysed separately and the relationship between their working hours and output was described by output-hours regressions in which hours were expressed in polynomials:
Linear:
Quadratic:
$X_{t}=\alpha_{0}+\alpha_{1} H_{t}+u_{1 t}$
Cubic:

$$
\begin{aligned}
& X_{t}=\beta_{0}+\beta_{1} H_{t}+\beta_{2} H_{t}^{2}+u_{2 t} \\
& X_{t}=\gamma_{0}+\gamma_{1} H_{t}+\gamma_{2} H_{t}^{2}+\gamma_{3} H_{t}^{3}+u_{3 t}
\end{aligned}
$$

In these equations, $X_{t}$ stands for output in week $t, H_{t}$ is hours worked in week $t$, and the $u_{i t}$ terms $(i=1,2,3)$ are stochastic components that embody unmeasured factors affecting output.

For each group of workers, the reduction in the calculated standard error of estimate of the equation suggests that the quadratic-in-hours and cubic-in-hours specifications are improvements in goodness of fit over the linear-in-hours specification. There was little to choose between the quadraticin-hours and cubic-in-hours: both imply output rises with hours but at a decreasing rate. The similarity across these four groups of workers in the fitted output-hours relationships prompts the question of whether these weekly observations on all the workers may be pooled and a single output-hours regression fitted to the entire set (allowing each group to have its own equation intercept). The leastsquares estimates of the coefficients attached to the work hours variables in equations (1) through (3) fitted to all 122 weekly observations are reported in Table 2 and the implied output-hours relation is graphed in Figure 3 for the quadratic and cubic specifications. ${ }^{26}$

The estimates of the quadratic-in-hours and the cubic-in-hours equations imply that the hours at which output is a maximum is at 67 and at 64, respectively. In fact, there are a few cases in which actual observations on hours of work exceed 67 and 64 meaning that, in these instances, average observed hours were at levels where the estimated marginal product of hours is negative! ${ }^{27}$ However, there are relatively few of these estimated negative marginal products and a more guarded inference

\footnotetext{
${ }^{26}$ Applying conventional F-distribution tests, the null hypothesis that the slopes of the output-hours relation were the same for the four groups of workers could not be rejected by conventional criteria.

${ }^{27}$ When the quadratic and cubic equations are fitted to the four groups of workers separately, it is also the case that there are some observed hours of work that exceed the hours at which the estimated output-hours relation reaches a maximum. This is true for the women turning fuze bodies and the youths boring top caps.
} 
would be that, at hours above 60, output is not highly sensitive to changes in work hours.

Out of concern that the equations fitted may not have provided sufficient flexibility to describe the output-hours relationship accurately, the observations were separated into two regimes: one regime corresponds to weekly hours less than 49 and the second regime consists of observations where hours are 49 and more. Spline functions were estimated that allow the output-hours relationship at less than 49 working hours to differ from the output-hours relation at 49 hours and beyond. Separate quadraticin-hours equations were estimated to the observations in the two hours regimes subject to the constraint that the two quadratic equations meet at 49 hours, the knot, where they also have the same derivatives. The knot was chosen at this value because working hours in many countries were reduced to 48 shortly after the War where it remained for two decades, suggesting it may have constituted a focal point. ${ }^{28}$ The implications of other knots were entertained though the 49 hour knot provided a superior fit. Descriptive statistics on output and hours in the two regimes are given in Table 3. To be explicit, the equation estimated is a quadratic-in-hours spline:

(4) $X_{t}=\left[a_{1}+b_{1}\left(H_{t}-H_{0}\right)+c_{1}\left(H_{t}-H_{0}\right)^{2}\right] D_{1 t}+\left[a_{2}+b_{2}\left(H_{t}-H_{1}\right)+c_{2}\left(H_{t}-H_{1}\right)^{2}\right] D_{2 t}+u_{4 t}$

where $D_{1 t}$ takes the value of unity for observations where working hours are less than 49 and of zero otherwise while $D_{2}$ takes the value of unity for observations where working hours are 49 hours or more and of zero otherwise. $H_{0}$ is set to 24 weekly hours, the lowest value observed, and $H_{1}$ is the knot of 49 hours. $a_{1}$ is allowed to be different for each of the four groups. The slope of the output-hours relation within each regime is restricted to be the same for workers in each group, a restriction that cannot be rejected by conventional tests. The least-squares estimates of the parameters on hours of work in equation (4) (the parameters $b_{1}, c_{1}, b_{2}$, and $c_{2}$ ) are reported in column (i) of Table 4 and the implied output-hours relation is plotted by the dotted line in Figure 4.

\footnotetext{
${ }^{28}$ A cubic-in-hours spline was also estimated, but its output implications at very short hours and at very long hours were implausible. The implications of other knots were entertained with little consequence for the output-hours relation. On 49 hours as the knot, “....some form of eight-hour [per day] legislation had been adopted by most western European countries by autumn 1919, and by most other industrial nations over the next two years. Meanwhile Britain, Italy, and the U.S. had moved to a 48-hour standard by collective agreements rather than legislation” (Scott and Spadavecchia (2011), p.1271). Also see Cross (1989).
} 
The fitted output-hours spline in Figure 4 resembles those curves in Figure 3 except that the relationship in the regime corresponding to working hours less than 49 appears close to linear. Indeed, the estimated parameter on the quadratic term in this regime, $c_{1}$, though negative, is less (in absolute value) than its standard error. Re-estimating equation (4) with $c_{1}$ restricted to zero yields the estimates in column (ii) of Table 4 whose output-hours implications are expressed by the solid line in Figure 4. The two curves in Figure 4 are virtually indistinguishable.

An implication of a linear relation between output and hours at hours less than 49 is that a loglinear fitted equation - as in equation (5) below - would yield a slope coefficient, $\delta_{1}$, of unity:

Log-linear: (5) $\quad \ln \left(X_{t}\right)=\delta_{0}+\delta_{1} \ln \left(H_{t}\right)+u_{4 t}$

The least-squares estimates of equation (5) (with fixed effects for each group of workers included) are contained in Table 5 where, for the shorter hours regime, the estimate of $\delta_{1}$ is, indeed, unity. ${ }^{29}$

The conclusion from the work presented in this section is that the output-hours relation is decidedly non-linear: below 49 weekly hours, variations in output are proportional to variations in hours; for those observations corresponding to 49 or more hours, output rises with hours at a decreasing rate and a maximum of output occurs at about 63 hours. Output at 70 hours differs little from output at 56 hours and, therefore, the HMWC's recommendations about the innocuous effects for output of hours reductions are consistent with these estimates.

Figure 4's total product curves imply the marginal product and average product curves drawn in Figure 5: the marginal product of hours is a constant until the knot at 49 hours after which it declines. The estimated marginal product of hours turns negative at 63 hours where output reaches a maximum. The average product of hours increases slightly with work hours at hours below 49 and reaches a maximum at 49 hours after which it falls as hours increase. ${ }^{30}$ Differences across hours in output per

\footnotetext{
${ }^{29}$ Recall from the Introduction that Denison (1962) guessed that, in terms of equation (5), $\delta_{1} \approx 0$ for hours at 49 and $\delta_{1}=0.6$ for hours at 40 . The estimate of $\delta_{1}$ in Table 5 fitted to munition workers are not significantly different from Denison's value at 49 hours, but exceed his guess for hours at 40 .

${ }^{30}$ Surveying U.S. firms heavily involved in aspects of armaments production in the Second World War, Brown and Baker (1942) identify 48 weekly hours as a threshold. They quote one executive: “....it is evident that 48 hours per week can be worked without ill effects either to the workman or the company's production.” By contrast, dissatisfaction with the length of the working week was expressed
} 
hour are small compared with differences in the marginal product of hours.

Sunday work

The HMWC was very critical of Sunday work. These data identify weeks when workers were employed on Sundays so that the HMWC's criticism may be evaluated. Naturally, those weeks involving Sunday work tended to be weeks with longer hours of work, but sometimes a given number of weekly hours was packed into fewer work days so longer hours do not require Sunday work. Indeed, is it the case that, as the HMWC alleged, holding weekly hours constant, the absence of a rest day (Sunday) damages weekly output?

This question is addressed for each of the four groups of workers separately and for all of them pooled together. The results were the same for all specifications fitted, for the groups of workers analysed separately and for the workers pooled together. Here simply one estimated equation is reported, that for the spline linear-in-hours below 49 hours and quadratic-in-hours at 49 hours and above. Column (iii) of Table 4 reports the results of adding a Sunday dummy variable to this specification. ${ }^{31}$ The estimated coefficient is negative and significantly less than zero by conventional criteria. Indeed, in all regressions of output and hours estimated, the coefficient on the Sunday variable is negative, significantly less than zero, while the shapes of the output-hours relation remain the same. The loss in output from denying workers a day of rest is about ten percent.

The importance of a day of rest may be inferred from the comparison of the output consequences of two work schedules: one schedule involves work of ten hours a day for seven days or 70 weekly hours including work on Sunday; the other schedule entails work of eight hours per day for six days (and no work on Sunday) or 48 weekly hours. The second schedule became the norm in many countries soon

by many companies with schedules from 50 to 58 hours a week. Schedules of 60 hours or more were characterized by “decreased productivity and increased absences, accidents, and labor turnover”.

${ }^{31}$ To be precise, for almost all weeks, it is a dummy variable implying all workers were either working on Sunday or all workers were not working on Sunday. For a few instances, for youths, some of them worked on Sunday and some did not. In these few cases, the Sunday variable is a fraction denoting the fraction of workers who worked on Sunday. The estimates in column (iii) of Table 4 distinguish between seven day working weeks and six day working weeks (holding weekly hours constant). Aggregate production functions that differentiate between working hours per day and working days per week are fitted by Hamermesh (1996) using contemporary data. 
after the War was concluded. Some munition workers were on the first schedule in 1914 and 1915. The estimates in column (iii) of Table 4 imply that output is slightly higher on the 48 hour working week (with no Sunday work) than on the seven day work schedule. The difference is small (merely 1.4 percent of the 70 hour output), but it illustrates the relevance of a day of rest and the relative insensitivity of output to increases in working hours above fifty hours. The HMWC's strictures against Sunday work are consistent with these estimates.

\section{B. Cross-Section Observations on Weekly Hours and Output of Individual Workers}

Whereas the data examined in the previous section consisted of observations on the weekly output and weekly hours worked of groups of workers, the data considered in this section are observations on 43 individual women munition workers collected by Ethel Osborne (1919). ${ }^{32}$ Her data on the average weekly output and the average weekly hours of work of individual women munition workers are from two workshops. Each workshop operated two different work schedules. The two schedules involved some individuals working at night and some during the day so her data provide an opportunity to compare day work with night work. A week of night work would alternate with a week of day work discontinuously. The shifts provided workers with one day of rest.

The work in this study involved the "ripping" or "part off” operation in shell turning. This is the first operation on the rough forging and it involves cutting the end of the forging to shorten it to the appropriate length. ${ }^{33}$ The women under study had worked on these operations for a period of about 18 months, on shifts of 12 hours duration. The measure of output is the average number of shells produced by a worker per week. Descriptive statistics on weekly output and weekly hours of work of these women are given in Table 6. The weekly work hours of these women range from a low of 25 hours

\footnotetext{
${ }^{32}$ Ethel Osborne worked for two years for the Ministry of Munitions and, for a while, was the head supervisor in a munitions factory. She undertook investigations both for the HMWC and for the Industrial Fatigue Research Board. After the War, she emigrated to Australia and had an illustrious career there. Her brother served on the Western Front and was killed in action.

${ }^{33}$ Osborne writes, “The operation is generally considered to be the hardest in shell-making for the shell is at its heaviest stage; and, further, the operation is a rapid one and entails constant changing of shells. In the case of the six inch shell the operation is particularly heavy....as the forging at this stage weighs about 140 lbs., the handling by pulleys of this amount of material into and out of the lathe constitutes a strenuous day’s work.”
} 
to a high of 63 hours with a central tendency not far from 40 hours. In other words, the work hours of these women tend to be lower than those workers described in Table 1 perhaps because the work undertaken by these women was more demanding. Whereas only 18 percent of the 122 weekly observations analysed in the previous section were observations where hours were equal to or less than 45 hours, 58 percent of these observations on individual women record weekly hours of 45 or less.

To describe the data on each worker's weekly work hours and her weekly production of shells, the equations specified in the previous section - equations (1) through (5) - were fitted to the output and hours observations. The estimated coefficients on the hours variables are listed in Table $7 .{ }^{34}$ In this instance, the quadratic specification appears little different from the linear specification though the cubic represents a better fit. The implications of the estimates of all three specifications and of the loglinear equation are contained in Figure 6. They are virtually indistinguishable from one another from which I conclude that, for these workers at this activity, a linear output-hours relation provides a compact approximation. In addition, the coefficient attached to $\ln H_{i}$ in the log-linear specification is not significantly different from unity and thereby consistent with the hypothesis that the marginal product of hours is independent of work hours. In other words, most of the observations on these individual women are in the hours regime corresponding to less than 49 weekly hours which was described, in the previous section, by a linear output-hours relationship. The finding of a linear outputhours relation for these individual women is, therefore, consistent with the results in the previous section.

However, is there a difference between the output-hours association of women working during the day and the women working at night? There are 27 women working during the day and 16 women working through the night. Separate least-squares estimates of the output-hours relation are derived and the simulated output-hours relation from the linear specification are pictured in Figure 7. At hours observed for both day and night workers, the output of the night workers is slightly above that of the day workers. The difference is negligible. Indeed, a formal test of the hypothesis that the output-hours equation for night workers is no different from that of day workers cannot be rejected. This finding holds for the estimates of the quadratic, cubic, and log-linear equations as well as for the

\footnotetext{
${ }^{34}$ The estimates corresponding to the quadratic-in-hours spline are not reported as the coefficient on the quadratic term for the regime corresponding to 49 or more hours was smaller than its standard error and the estimated marginal product of hours was mildly rising at long hours.
} 
linear. This supports the HMWC's conclusion that, on the discontinuous system of alternating a week of day work with a week of night work, there is no significant difference between output on the night and day shifts and, if anything, output is higher on the night shifts.

C. Hours and Output over the Day and over the Night

In addition to the observations on weekly output and weekly work hours on individual women workers described in the previous section, Osborne reported on the output of groups of women each hour of the day or night. These women were engaged in the same operation of shell production as those women described in the previous section. With the data investigated in this section, not only does Osborne supply information on shells produced during each hour of the shift, she also provides data on the number of women workers. Moreover, her period of observation spans a time when new machinery was introduced that made the work less onerous. ${ }^{35}$ Consequently, some of her hours and output observations are from a time before the new machinery was introduced and some observations are taken after the new machinery has been installed. The output-hours relation will be described after taking account of variations in two other inputs: the number of workers and the vintage of the machinery.

There are 77 hourly observations on output, 33 of them on the day shift and 44 on the night shift. Each shift involves 101/2 hours of actual work. The day shift starts at 6.00 a.m. and ends at 6.00 p.m.; there is a mid-morning break of half-an-hour and an hour's meal break from 1.00 to 2.00 p.m. The night shift starts at 6.00 p.m. and ends at 6.00 a.m. There is a break from 9.00 to 10.00 p.m. and another break from 1.30 to 2.00 a.m. The workshops maintained the discontinuous system described earlier whereby a week of night work would be followed by a week of day work. This means that the night and day observations on output are on the same workers. The workers had one day each week of not working.

Is there evidence of fatigue in the output of these workers? That is, as hours of work lengthen over the day and night, after a point, do women produce less each hour. If $x_{j}$ is the output of shells

\footnotetext{
35 The new machines “....considerably reduced the demands made on the women for violent physical exertion. The old system of chuck and crowbar clamping was replaced by a jaw clamp, in which the shell forging was comparatively easily fixed, and the violent jerks necessary to secure the forging were no longer required. Further, the level at which the shell was fixed was lower and more convenient for the women workers. Lastly, the cutting itself was automatic, whereas formerly the tool required constant guidance by the operator. In spite of these modifications, this operation was still considered very heavy...” (Osborne (1919, p.4))
} 
during the $j$ th hour since work started on a shift and if $h_{j}$ denotes hours worked (excluding any break) since the beginning of work, after a point, does $x_{j}$ fall as the duration of work hours lengthen? Defining the marginal product of hours as the amount added to total product by working one more hour, then $x_{j}$ is a discrete measure of the marginal product of hour $j$. Therefore, asking whether $x_{j}$ falls as $h_{j}$ increases is tantamount to asking whether the law of diminishing returns holds for work hours.

Table 8 contains descriptive statistics on the hours worked of these workers since the beginning of their work and on their output of shells produced each hour. The hourly output of the night shift is higher than that of the day shift though there tends to be more workers on the night shift. The following equations were specified and estimated to these observations on output each hour and the number of hours worked since the beginning of the day or night:

Linear: (6)

Quadratic: (7)

Cubic:

Log-linear: (9)

$$
\begin{aligned}
& x_{j}=\mu_{0}+\mu_{1} h_{j}+\mu_{2} L_{j}+\mu_{3} K_{j}+\mu_{4} N_{j}+u_{6 j} \\
& x_{j}=\eta_{0}+\eta_{1} h_{j}+\eta_{2} h_{j}^{2}+\eta_{3} L_{j}+\eta_{4} K_{j}+\eta_{5} N_{j}+u_{7_{j}} \\
& x_{j}=v_{0}+v_{1} h_{j}+v_{2} h_{j}^{2}+v_{3} h_{j}^{3}+v_{4} L_{j}+v_{5} K_{j}+v_{6} N_{j}+u_{8 j} \\
& \ln \left(x_{j}\right)=\lambda_{0}+\lambda_{1} \ln \left(h_{j}\right)+\lambda_{2} L_{j}+\lambda_{3} K_{j}+\lambda_{4} N_{j}+u_{9 j}
\end{aligned}
$$

In these equations, $L_{j}$ denotes the number of workers at work during hour $j, K_{j}$ is a dummy variable that takes the value of unity when the work is performed with the newer vintage of machinery and of zero otherwise, and $N_{j}$ is a dummy variable that takes the value of unity for an observation from the night shift and of zero otherwise. The $u_{i j}$ terms ( $i=6,7,8,9$ ) are stochastic components that incorporate the effects of omitted variables.

The least-squares estimates of the parameters of equations (6) through (9) as fitted to all 77 (Day plus Night) observations are reported in Table 9 and Figure 8 simulates the relationship between the marginal product of hours (that is, the additional output produced during each hour) and hours since starting work as implied by the least-squares estimates of the equations. The linear and log-linear specifications show marginal products declining throughout the shift whereas the other equations have an interval of initially rising marginal products before they turn down (after about $4 \frac{1}{2}$ hours for the quadratic specification and after about 6 hours for the cubic equation). In short, these estimates of the marginal product of hours over the day and night take the form that are often drawn in textbooks: when the functional form permits, the marginal product of hours worked rises with hours and then, when diminishing returns set in, declines. In these data, the region of diminishing marginal product operates over much of the working day. However, marginal products never turn negative so that a shorter 
working day implies a loss of output (holding constant the number of working days).

In all cases, the marginal product of hours over the day or night is a positive function of employment $\left(L_{j}\right)$ and is higher for the output produced with the newer vintage machinery ( $K_{j}$ ). In addition the estimated coefficient on the night shift dichotomous variable $\left(N_{j}\right)$ is always positive and significantly greater than zero. According to the log-linear estimates, output per hour is about 18 percent higher when the workers use the new machinery and about 9 percent higher on the night shift over the day shift. To pursue the day-night distinction, equations (6) through (9) were fitted to the day and night observations separately and the estimated relationship between output each hour and the number of hours since starting work are graphed in Figure 9 for the quadratic-in-hours specification, equation

(7). The marginal product of hours worked at night is clearly larger than that of hours worked during the day. ${ }^{36}$

\section{Some Conclusions about Hours and Output of Munition Workers}

The estimates above on the output-hours relationship suggest that, for most workers, weekly output rises with weekly hours of work although, after a point, the increase in output declines as more hours are worked. This point where the marginal product starts to decline varies with the workers and with the work done. For hours of 48 or less, weekly output tends to be proportional to weekly hours worked and the decline in the marginal product of hours occurs after 48 weekly hours. The decline in marginal products is not clear for the cross-section observations on 43 individual women where a linear output-hours representation describes the data well at all observed hours. This underlines the inference that, although a concave-from-below output-hours relation is common at long hours, the particular shape of the relation varies across workers and across types of work.

The diurnal data on the additional output produced in an hour are interpreted as observations on a discrete measure of the marginal product of hours worked over the day or night. These observations describe marginal products as rising over the first few hours of work and then declining.

These findings are broadly consistent with the HMWC's recommendations. Increases in output as hours rise beyond 50 in a week are relatively small so that the sorts of reductions in weekly hours and in daily hours that the HMWC urged would have implied small reductions in output. A reduction

\footnotetext{
${ }^{36}$ Allowing the output-hours relationship to differ between the hours worked before the one hour break in mid-shift and the hours worked after this break did not result in any clear implications.
} 
in working time effected by eliminating working on Sunday would have had positive consequences for output. The absence of a day of rest each week had damaging effects on output, as the HMWC affirmed. The HMWC believed that night work was no less productive -- possibly, more productive -than day work provided the work schedule alternated a week of night work with a week of day work. Our results confirm the Committee's judgment. The reason for this superior output at night is not due to an evident selection effect -more efficient workers choosing to or assigned to work on the night shift because these are the same individuals who are working one week during the day and the next week at night.

\section{Implications of the Productivity of Working Hours}

There is a large empirical literature in Economics in which researchers relate observations on the hours of market work of individuals to observations on their hourly earnings and other variables and in which the fitted relationship is interpreted as a labor supply function. ${ }^{37}$ Rarely is the basic identification question addressed: as a quantity (hours) and price (wage) relationship, why is this equation a supply function and not a demand function or some hybrid relation? In fact, this question was taken up by Lewis (1957) in an article written almost sixty years ago in which he offered an explanation for the decline in the length of the working week since the end of the nineteenth century.

The patterns that Lewis addressed are displayed in Figure 10. This shows the movements in average real hourly compensation and in average weekly hours of work of production workers in U.S. manufacturing industry since 1890. Whereas real wages follow an upward trend (until the 1970s), hours of work decline until the Second World War and exhibit little or no trend after 1950.

Writing in the 1950s, to account for these movements, Lewis suggested that, "to a first approximation", in a figure with the real wage on the vertical axis and the hours worked by an individual on the horizontal axis, the typical employer's demand for work hours is infinitely elastic at a given wage rate. According to Lewis' argument, the typical employer cares about the aggregate hours worked by the firm's entire work force but, at the given wage, the employer is willing to allow each worker to set his or her own work hours according to the worker's income-leisure preferences. This horizontal derived demand curve for hours of work shifted upwards over time as the economy grew,

\footnotetext{
${ }^{37}$ A recent authoritative review of this research is Keane (2011).
} 
real incomes rose, and the derived demand for labor increased. The fact that, while real compensation rose, hours fell (at least until 1940) implies, with an assumed unchanged labor supply curve, that this supply curve is negatively sloped and the income effect exceeds the substitution effect. Figure 11 depicts Lewis’ proposed explanation: the location of the firm’s horizontal demand curve for hours sets the real wage (so wages are independent of the shape and location of the supply of hours) and, at this wage, the supply curve of hours determines the worker's working hours. This provides the justification for interpreting a regression of the hours of work of individuals on their real wages as a labor supply function. ${ }^{38}$

A decade later, Lewis (1969) wrote another paper on work hours that was published in a Spanish-language journal. An English-language version of this paper titled "Employer's Interests in Employee's Hours of Work" has circulated for over forty years. In this later paper, Lewis altered his earlier framework and replaced it with one in which an employer did care about the hours worked by each employee. The amendment that generated this change was to distinguish between a firm's labor costs that vary with the number of workers employed and labor costs that varied with hours of work. Others have called this a distinction between fixed and variable labor costs. ${ }^{39}$

This paper has considered a different reason for an employer not to be indifferent to the work

\footnotetext{
${ }^{38}$ According to Lewis, years of heavy unemployment and effective hours of work regulation caused hours to diverge from those pictured in Figure 11 and, in these periods, the hours-wage observations were off the worker's supply curve. If the years of the Depression and the years of the Second World War are avoided (that is, using annual observations from 1890 to 1930), a least-squares regression of the logarithm of the average weekly hours of production workers in manufacturing industry on the logarithm of the average real hourly compensation of these workers yields a coefficient on compensation of -0.269 with an estimated standard error of 0.016 . Thus, according to Lewis' hypothesis in his 1957 paper, the elasticity of the supply of hours of manufacturing workers with respect to their wages is -0.269 .

${ }^{39}$ Lewis (1969) described those costs that are independent of hours worked as including "the costs of searching for and recruiting employees, maintaining payroll and other records for them. Orienting them to the foibles of their work and work environment, supervising and policing their work, and so on”. In the literature on fixed and variable costs, Sherwin Rosen's (1968) paper on the railroads is frequently and appropriately referenced. This paper was a part of Rosen's thesis written under Lewis' supervision. Later Rosen's (1974) well-known article on hedonics and implicit markets references and resembles in form Lewis' 1969 paper on “Employer's Interests in Employee’s Hours of Work”. Another important contribution in this vein at this time was Ehrenberg's (1971) link between absenteeism and the use of overtime hours.
} 
hours of each employee, namely, the diminishing productivity associated with an individual working long hours. The findings earlier in this paper suggest Lewis' hypothesis that output is proportional to working hours is, indeed, an appropriate “first-order approximation" to working hours -- up to a certain threshold. Beyond this threshold, increases in working hours raise output at a diminishing rate. This applies to hours worked over the week and to hours worked over the day. The working week threshold for the munition workers considered in this paper was at 48 hours, but for other workers it may be more or less.

If this 48 hours threshold applied also to the manufacturing workers whose wages and hours are graphed in Figure 10, then the assumed horizontal marginal product of hours curve pictured in Figure 11 does not apply to the period before 1920 because, in these years, the average weekly hours of production workers in manufacturing industry exceeded 48. An alternative representation is pictured in Figure 12 where the demand for hours function $D D$ is kinked at $H^{*}$ just as that graphed by the solid line in Figure 5. At hours less than $H^{*}$, the demand for hours is that suggested by Lewis: a horizontal schedule that expresses an employer's indifference to the number of hours worked by an employee. At hours more than $H^{*}$, the marginal product of hours falls as hours lengthen.

Figure 12 also supposes a limiting case (but, to economists, a familiar one) for the supply of an input: the firm is a price-taker in input markets and faces a horizontal supply of hours schedule. At a given wage, the worker is willing to work any hours that the employer demands. This is the inverse of the situation posed by Lewis: in Figure 12, the wage is set by the location of the supply of hours function and work hours are determined by the employer's demand for hours. Figure 12 shows the horizontal supply of hours function moving up over time because of competition among firms for the hours of workers or because of trade union pressure on wages or because of minimum wage regulation. $^{40}$ The hours-wage observations trace out the firm's negatively-sloped hours demand function, not a negatively-sloped supply of hours function, as Lewis proposed in 1957. In fact, suppose that, over the years 1890-1920, the output-hours relationship follows the quadratic-in-hours equation (2). Then the profit-maximizing firm's first-order condition for working hours corresponding to that expressed in Figure 12 can be written as $H_{t}=\theta_{0}+\theta_{1}(w / p)_{t}$ where $\theta_{1}=\left(2 \beta_{2}\right)^{-1}$. When the stochastic version of this first-

\footnotetext{
40 This reversal of Lewis' horizontal demand function for hours with a horizontal supply function of hours was entertained also by Ehrenberg (1971).
} 
order condition is fitted to the 1890-1920 manufacturing weekly hours and real hourly compensation observations, the estimated value of $\theta_{1}$ is -7.629 (0.656) which implies a value of -0.066 for $\beta_{2}$. The elasticity of demand for hours with respect to wages is -0.267 evaluated at average hours and wages.

The outcome sketched in the previous paragraph -- where the labor supply curve is infinitely elastic -- is not the most likely setting. More plausible is the case in which the hours of work supply function is not horizontal, but one in which the work hours supplied to a firm by a typical worker is responsive to changes in wages. In this case, hours of work are a function both of variables that shift the employer's marginal revenue product of hours of work and the worker's supply of work hours and the identification of one or other relationship is not straightforward.

\section{VI. $\underline{\text { Conclusions }}$}

This re-examination of the recommendations relating to hours of work of the HMWC finds them broadly consistent with our analysis: at the levels of working hours in 1915 and 1916 during the War, hours reductions would have had small or no damaging effects on output; those weeks without a day of rest from work had about ten percent lower output than weeks when there was no work on Sunday holding weekly hours constant; night work was not less productive than day work and, indeed, may have been slightly more productive.

Long weekly hours and long daily hours do not necessarily yield high output and this implies that, for some employees engaged in certain types of work, their profit-maximizing employer will not be indifferent to the length of their working hours over a day or week. This point has already been made in the literature of fixed employment costs where costs linked to the number of workers employed inclines a firm to extend the working hours of employees. This paper has suggested a different reason for an optimizing employer to care about the length of working hours: employees at work for a long time may experience fatigue or stress that not only reduces his or her productivity but also increases the probability of errors, accidents, and sickness that impose costs on the employer. Unlike the case of fixed employment costs, these concerns over work stress incline the firm not to extend the work hours of employees, but to curtail them. The point at which fatigue sets in and the nature of the link between working hours and work effort or fatigue is likely to vary across types of work and across workers.

This is certainly not a new argument, but it seems to have been neglected in contemporary models of labor markets. It implies that restrictions on working hours - those imposed by statute or 
those induced by setting penalty rates of pay for hours worked beyond a threshold or those embodied in collective bargaining agreements - may be viewed not as damaging restraints on management but as an enlightened form of improving workplace efficiency and welfare.

However, why should an employer resist cutting working hours: if workers' earnings are tied to their hours of work, then fewer hours imply lower labor costs and, if shorter hours yield the same output, why would any firm knowingly select the higher hours? Even if workers are paid entirely by results and not by time worked, there are ancillary costs of long working hours such as the expenses of running complementary machinery and of providing light, heat, ventilation, and supervisory labor. Is it possible that employers were unaware that hours could be reduced without loss of output?

This was the opinion of Hicks (1932, 1963, Ch. V) who believed that "probably it has never entered the heads of most employers that it was at all conceivable that hours could be shortened and output maintained. But it is clear that there were a few who had realised it." Hicks explains why competition among firms might not induce a cut in hours and why, in the absence of statutory regulation or the activities of trade unions, employers have been "slow" to initiate a reduction in hours. ${ }^{41}$

As for the measurement of the labor input in production, although it may be appealing to combine the number of workers and their average hours of work into a single variable called workerhours, there is also a case for unbundling them and for allowing working hours to enter production differently from the number of workers. Moreover, the use of average hours may be troublesome if there are sharp differences among workers in their hours and if the results in this paper apply; in this case, the average may be an especially inappropriate summary indicator of a highly nonlinear effect. At 35 hours, an additional five hours to the length of the working week has consequences for the effective labor input that are quite different from an additional five hours starting at 48 hours.

This argument also has the implication that the conventional procedure in estimating labor supply functions with observations on work hours and wages is frustrated by the conventional identification problem of distinguishing the supply function from the demand function in these quantity

${ }^{41}$ Similarly, Vernon (1940, p.7) believed many employers lacked knowledge of these relationships: “......in spite of what employers might reasonably have been expected to know about the physical capabilities of their workers in the munition factories of 1914-18, they in many cases acted in direct opposition to the well-supported evidence supplied by earlier investigations, and subjected their employees to unwarrantable conditions of work.” 
(hours) and price (wage) observations. No doubt, there are individuals whose working hours are well described by the situation pictured in Figure 11. There are others for whom the market expressed in Figure 12 will provide a closer approximation.

Do the HMWC's concerns about long work hours have any relevance for today's workplaces? A number of recent studies show that accidents and illnesses follow long work hours. For instance, an analysis of over ten thousand workers from the National Longitudinal Survey of Youth between 1987 and 2000 found that, holding constant a number of other factors, those who worked at least twelve hours each day or at least sixty hours per week had considerably higher (37 percent and 23 percent, respectively) injury hazard rates than other workers. Long hours typify certain jobs and research has documented untoward consequences of long hours in these occupations. In a study of hospital staff nurses, shifts longer than 12 hours and working weeks longer than 40 hours were associated with significantly heightened probabilities of error that have raised questions about patient safety. In another study, medical interns were significantly more likely to be involved in motor vehicle crashes if they had just worked extended shifts. ${ }^{42}$ Similar reports have been made about airline pilots, police officers, truck drivers, and soldiers.

Work fatigue and work stress are not confined to these occupations. In a nationally representative survey of almost 30,000 U.S. workers interviewed between August 2001 and May 2003, almost 38 percent replied affirmatively to the question, "Did you have low levels of energy, poor sleep, or a feeling of fatigue in the past two weeks?” Full-time workers were more likely to lose productive time from fatigue than those working part-time. In addition, in 2002, according to the Health and Retirement Survey, one-fifth of workers aged 55 to 60 years strongly agreed with the description of their current job as involving “a lot of stress”.

If the analysis here were repeated on contemporary data that contain information on workers' output and their working hours, we might be able to assess Denison’s (1962, p.39) judgment that “Few studies offer more promise of adding to welfare and contributing to wise decisions in a matter that may greatly affect the future growth rate than a really thorough investigation of the present relationship between hours and output.”

\footnotetext{
42 The studies in this and the next paragraph are found in Barger et al. (2005), Dembe et al. (2005), Rogers et al. (2004), Ricci, et al. (2007), Johnson (2004), and Rho (2010). Also see Vegso et al. (2007).
} 


\section{REFERENCES}

Agnew, T.H., "Report on the Health and Physical Condition of Male Munition Workers”, Interim Report of the Health of Munition Workers Committee, 1917, Cmd. 8511.

Bandiera, Oriana, Iwan Barankay, and Imran Rasul, "Field Experiments with Firms”, Journal of Economic Perspectives , 25 (3), Summer 2011, 63-82

Barger, Laura K., Brian E. Cade, Najib T. Ayas, John W. Cronin, Bernard Rosner, Frank Speizer, Charles A. Czeisier, “Extended Work Shifts and the Risk of Motor Vehicle Crashes among Interns”, New England Journal of Medicine, 2005, 352 (2), January 2005, 125-34.

Barker, Pat, Regeneration, Penguin Books, London, 1992.

Bedford, Thomas, “H.M.Vernon, M.A., M.D.”, Occupational Medicine 1(1), 1951, 47-8.

Brown, David G., "Hours and Output” in C.E.Dankert, F.C.Mann, and H.R.Northrup, eds., Hours of Work, Industrial Relations Research Association, Publication No. 32, Harper \& Row, New York, 1965, pp. 147-60.

Brown, J. Douglas, and Helen Baker, Optimum Hours of Work in War Production, Industrial Relations Section, Princeton University, March 1942.

Campbell, Janet M., and Lilien E. Wilson, “Inquiry into the Health of Women Engaged in Munition Factories”, Interim Report of the Health of Munition Workers Committee, 1917, Cd. 8511.

Cross, Gary, A Quest for Time: The Reduction of Work in Britain and France, 1840-1940, University of California Press, Berkeley, 1989. 
Dembe, A.E., J.B.Erickson, R.G.Delbos, and S.M. Banks, “The Impact of Overtime and Long Work Hours on Occupational Injuries and Illnesses; New Evidence from the United States", Occupational and Environmental Medicine, 62 (9), September 2005, 588-97.

Denison, Edward F., The Sources of Economic Growth in the United States and the Alternatives Before Us, Committee for Economic Development, New York, 1962 .

Drake, Barbara, Women in the Enginering Trades, Trade Union Series No. 3, Fabian Research Department and George Allen \& Unwin, London, 1917

Ehrenberg, Ronald G., Fringe Benefits and Overtime Behavior, D.C. Heath and Co., Lexington, 1971.

Feldstein, M.S., "Specification of the Labour Input in the Aggregate Production Function”, Review of Economic Studies, 34 (4), October 1967, 375-86

Goldmark, Josephine, Fatigue and Efficiency: A Study in Industry, Russell Sage Foundation, New York, 1912.

Hamermesh, Daniel S., Labor Demand, Princeton University Press, Princeton, 1993.

Hamermesh, Daniel S., Workdays, Workhours and Work Schedules: Evidence for the United States and Germany, Upjohn Institute, Kalamazoo, 1996.

Harrison, Glenn W., and John A. List, “Field Experiments”, Journal of Economic Literature, 42 (4), December 2004, 1009-53.

Hart, Robert A., and Peter G. McGregor, "The Returns to Labour Services in West German Manufacturing Industry”, European Economic Review, 32, 1988, 947-63. 
Hart, Robert A., “Women doing Men’s Work and Women doing Women’s Work: Female Work and Pay in British Wartime Engineering”, Explorations in Economic History, 44, 2007, 114-130.

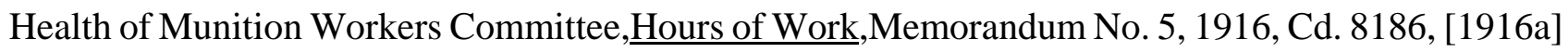

Health of Munition Workers Committee, $\underline{\text { Statistical Information Concerning Output in Relation to }}$ Hours of Work, Memorandum No. 12, 1916, Cd. 8344, [1916b]

Health of Munition Workers Committee, Interim Report, Industrial Efficiency and Fatigue, 1917, Cd. 8511.

Health of Munition Workers Committee, Further Statistical Information concerning Output in relation to Hours of Work, with Special Reference to the Influence of Sunday Labour, Memorandum No. 18, 1917, Cd. 8628.

Health of Munition Workers Committee, Weekly Hours of Employment, Memorandum No. 20, 1917, Cd. 8801.

Health of Munition Workers Committee, Final Report, 1919, Cd. 9065 and reprinted by the U.S. Bureau of Labor Statistics, Bulletin 249.

Hicks, J.R., The Theory of Wages, Macmillan, London, first edition 1932, second edition 1963.

Johnson, Richard W., “Trends in Job Demands among Older Workers, 1992-2002" , Monthly Labor $\underline{\text { Review }}$, July 2004, 127(7), 48-56.

Jones, Ethel B., “New Estimates of Hours of Work per Week and Hourly Earnings, 1900-1957", Review of Economics and Statistics, 45(4), November 1963, 374-85. 
Keane, Michael P., “Labor Supply and Taxes: A Survey”, Journal of Economic Literature, 59(4), December 2011, 961-1075

Kossoris, Max D., and Reinfried F. Kohler, Hours of Work and Output, U.S. Department of Labor, Bureau of Labor Statistics, Bulletin No. 917, 1947.

Leslie, Derek, and John Wise, “The Productivity of Hours in U.K. Manufacturing and Production Industries”, Economic Journal 90(357), March 1980, 74-84

Lewis, H. Gregg, "Hours of Work and Hours of Leisure”, Proceedings of the Ninth Annual Meeting, of the Industrial Relations Research Association, ed. by L. Reed Tripp, 1957, pp. 196-206

Lewis, H. Gregg, "Employer Interests in Employee Hours of Work”, 1969, a version of which was published as “Interes del empleador en las horas de Trabajo del empleado” in Cuadernos de Economia, Catholic University, Chile.

Loveday, Thomas, “The Causes and Conditions of Lost Time”, Health of Munition Workers Committee, Interim Report, Industrial Efficiency and Fatigue, 1917,(Cd. 8511), pp 41-67.

Marti, Michael, “Substitution between Working Hours and Employment: An Empirical Analysis for Switzerland”, Swiss Journal of Economics and Statistics, September 2000, vol. 136 (3), pp. 397-415

Matthews, R.C.O., C.H.Feinstein, and J.C.Odling-Smee, British Economic Growth 1856-1972, Stanford University Press, California, 1982.

McIvor, A.J., "Employers, the Government, and Industrial Fatigue in Britain, 1890-1918", British Journal of Industrial Medicine, 44, 1987, 724-32

Ministry of Munitions, History of the Ministry of Munitions, Volume III Finance and Contracts, Part II Contracts, 1922. 
National Industrial Conference Board, Analysis of British Wartime Reports on Hours of Work as Related to Output and Fatigue, No. 2, November 1917, Boston, Mass.

Officer, Lawrence H., Two Centuries of Compensation for U.S. Production Workers in Manufacturing, Palgrave Macmillan, New York, 2009.

Osborne, Ethel E., “The Output of Women Workers in Relation to Hours of Work in Shell-Making”, Report No. 2 of the Industrial Fatigue Research Board, London, 1919.

Rho, Hye Jin, “Hard Work? Patterns in Physically Demanding Labor among Older Workers”, Center for Economic and Policy Research, Washington, D.C.,August 2010.

Ricci, Judith A., Elsbeth Chee, Amy L. Lorandeau, and Jan Berger, "Fatigue in the U.S. Workforce: Prevalence and Implications for Lost Productive Work Time”, Journal of Occupational and Environmental Medicine, 49 (1), January 2007, 1-10.

Rogers, Ann E., Wei-Ting Hwang, Linda D. Scott, Linda H. Aiken, and David F. Dinges, “The Working Hours of Hospital Staff Nurses and Patient Safety”, Health Affairs, 23(4), July/August 2004, 202-12.

Rosen, Sherwin, "Short-Run Employment Variation on Class-I Railroads in the U.S., 1947-1963", Econometrica, 36 (3/4), July-October 1968, 511-29.

Rosen, Sherwin, “Hedonic Prices and Implicit Markets: Product Differentiation in Pure Competition”, Journal of Political Economy, 82(1), January-February 1974, 34-55.

Rubin, Gerry R., War, Law, and Labour: The Munition Acts, State Regulation, and the Unions, 19151921, Clarendon Press, Oxford, 1987

Scott, Peter, and Anna Spadavecchia, “Did the 48-Hour Week Damage Britain's Industrial Competitiveness?”, Economic History Review, 64 (4), 2011, 1266-1288. 
Vegso, S., L. Cantley, M. Slade, O. Taiwo, K. Sircar, R. Rabinowitz, M.Fiellen, M.B.Russi, and M.R.Cullen, "Extended Work Hours and Risk of Acute Occupational Injury: A Case-Crossover Study of Workers in Manufacturing”, American Journal of Industrial Medicine, 50(8), August 2007, 597-603.

Vernon, Horace Middleton, Industrial Fatigue and Efficiency, Routledge, London, 1921.

Vernon, Horace Middleton, The Health and Efficiency of Munition Workers, Oxford University Press, London, 1940.

Woollacott, Angela, On Her Their Lives Depend: Munitions Workers in the Great War, University of California Press, Berkeley, 1994. 
Table 1

Descriptive Statistics on Weekly Hours and Weekly Output of Munition Workers

\begin{tabular}{|c|c|c|c|c|c|c|c|c|c|c|}
\hline & \multicolumn{2}{|c|}{$\begin{array}{c}100 \text { Women in } \\
\text { "Moderately } \\
\text { Heavy } \\
\text { Labour" }\end{array}$} & \multicolumn{2}{|c|}{$\begin{array}{l}40 \text { Women in } \\
\text { "Light } \\
\text { Labour" }\end{array}$} & \multicolumn{2}{|c|}{$\begin{array}{c}56 \text { Men in } \\
\text { "Heavy } \\
\text { Labour” }\end{array}$} & \multicolumn{2}{|c|}{$\begin{array}{c}15 \text { Youths in } \\
\text { "Light } \\
\text { Labour" }\end{array}$} & \multicolumn{2}{|c|}{$\begin{array}{l}\text { All Four } \\
\text { Groups of } \\
\text { Workers }\end{array}$} \\
\hline & hours & output & hours & output & hours & output & hours & output & hours & output \\
\hline nobs & \multicolumn{2}{|c|}{56} & \multicolumn{2}{|c|}{26} & \multicolumn{2}{|c|}{31} & \multicolumn{2}{|c|}{9} & \multicolumn{2}{|c|}{122} \\
\hline mean, $\mu$ & 53.1 & 6,654 & 49.2 & 5,889 & 47.2 & 6,066 & 56.8 & 6,645 & 51.1 & 6,341 \\
\hline median, $M$ & 52.3 & 6,861 & 49.4 & 6,177 & 49.9 & 6,246 & 54.7 & 6,811 & 50.6 & 6,514 \\
\hline $1^{\text {st }}$ quartile, $Q_{1}$ & 47.4 & 6,196 & 45.0 & 5,445 & 45.9 & 5,664 & 52.8 & 6,136 & 47.0 & 5,875 \\
\hline 3rd quartile, $Q_{3}$ & 61.1 & 7,338 & 55.4 & 6,490 & 51.4 & 6,874 & 56.2 & 7,194 & 56.1 & 7,063 \\
\hline minimum & 24.0 & 2,919 & 26.4 & 3,142 & 27.1 & 3,614 & 47.4 & 5,878 & 24.0 & 2,919 \\
\hline maximum & 71.8 & 8,735 & 64.9 & 7,063 & 59.1 & 7,738 & 72.5 & 7,325 & 72.5 & 8,735 \\
\hline standard deviation, $\sigma$ & 10.5 & 1,172 & 9.3 & 1,021 & 8.5 & 1,086 & 8.5 & 576 & 10.0 & 1,127 \\
\hline$\sigma / \mu$ & 0.20 & 0.18 & 0.19 & 0.17 & 0.18 & 0.18 & 0.15 & 0.09 & 0.20 & 0.18 \\
\hline$\left[1 / 2\left(Q_{3}-Q_{1}\right)\right] \div M$ & 0.13 & 0.08 & 0.11 & 0.08 & 0.06 & 0.10 & 0.03 & 0.08 & 0.09 & 0.09 \\
\hline
\end{tabular}

“nobs” means number of weekly observations. 
Table 2

Least-Squares Estimates of the Coefficients on Working Hours (and Estimated Standard Errors in Parentheses) of the Output-Hours Equations (1) through (3) Fitted to all 122 Weekly Observations.

\begin{tabular}{|c|c|c|c|}
\hline \multirow[t]{2}{*}{$\begin{array}{l}\text { RHS } \\
\text { variable }\end{array}$} & \multicolumn{3}{|c|}{$\begin{array}{l}\text { estimated coefficients (and estimated standard errors in } \\
\text { parentheses) attached to variables listed in the first column }\end{array}$} \\
\hline & equation (1) & equation (2) & equation (3) \\
\hline \multirow[t]{2}{*}{$H_{t}$} & 86.592 & 313.843 & 18.215 \\
\hline & $(6.665)$ & $(34.540)$ & (204.010) \\
\hline \multirow[t]{2}{*}{$H_{t}{ }^{2}$} & & -2.327 & 4.067 \\
\hline & & $(0.349)$ & (4.363) \\
\hline \multirow[t]{2}{*}{$H_{t}^{3}$} & & & -0.044 \\
\hline & & & $(0.30)$ \\
\hline$H^{x \max }$ & $N D$ & 67.4 & 64.0 \\
\hline \multicolumn{4}{|c|}{ goodness of fit statistics } \\
\hline$R^{2}$ & 0.628 & 0.731 & 0.736 \\
\hline see & 699.1 & 596.9 & 593.9 \\
\hline
\end{tabular}

These equations are fitted to all workers and they include fixed effects that allow the intercept of the output-hours equation to be different for each group of workers. The same output-hours slope applies to all the workers. see is the standard error of estimate of the equation and $H^{x m a x}$ is the hours of work at which output reaches a maximum as implied by the estimates of the fitted equation. The form of equation (1) does not permit such a stationary value and $N D$ means "not defined". 
Table 3

Descriptive Statistics on Weekly Hours and Weekly Output for Observations in the Shorter Hours Regime (Hours < 49) and in the Longer Hours Regime (Hours $\geq 49$ )

\begin{tabular}{|l|c|c|c|c|}
\hline & \multicolumn{2}{|c|}{ Hours $<49$} & \multicolumn{2}{c|}{ Hours $\geq 49$} \\
\hline nobs & \multicolumn{2}{|c|}{47} & Hours & Output \\
\hline & Hours & Output & 56.7 & $6,892.3$ \\
\hline mean, $\mu$ & 42.0 & $5,461.1$ & 54.9 & $6,892.2$ \\
\hline median, $M$ & 45,3 & $5,691.6$ & 51.2 & $6,490.0$ \\
\hline $1^{\text {st }}$ quartile, $Q_{1}$ & 38.5 & $4,648.2$ & 61.4 & $7,250.0$ \\
\hline $3^{\text {rd }}$ quartile, $Q_{3}$ & 47.6 & $6,230.7$ & 49.1 & $5,313.6$ \\
\hline minimum & 24.0 & $2,919.2$ & 72.5 & $8,037.6$ \\
\hline maximum & 48.8 & $8,735.2$ & 6.57 & 562.83 \\
\hline standard deviation, $\sigma$ & 7.6 & $1,242.67$ & 0.116 & 0.082 \\
\hline$\sigma / \mu$ & 0.181 & 0.228 & 0.093 & 0.055 \\
\hline$\left[1 / 2\left(Q_{3}-Q_{\nu}\right)\right] \div M$ & 0.100 & 0.139 & & \\
\hline
\end{tabular}


Table 4

Least-Squares Estimates of the Coefficients on Working Hours (and Estimated Standard Errors in Parentheses) of Output-Hours Spline Functions Fitted to All 122 Weekly Observations

\begin{tabular}{|c|c|c|c|}
\hline & column (i) & column (ii) & column (iii) \\
\hline parameters & $\begin{array}{c}\text { Quadratic-in-Hours in } \\
\text { Both Shorter Hours } \\
\text { and Longer Hours } \\
\text { Regimes }\end{array}$ & \multicolumn{2}{|c|}{$\begin{array}{l}\text { Linear-in-Hours in Shorter Hours Regime and } \\
\text { Quadratic-in-Hours in Longer Hours Regime }\end{array}$} \\
\hline \multicolumn{4}{|c|}{$<49$ hours regime } \\
\hline$b_{1}$ & $\begin{array}{l}153.040 \\
(34.209)\end{array}$ & $\begin{array}{l}126.089 \\
(8.036)\end{array}$ & $\begin{array}{l}144.192 \\
(7.307)\end{array}$ \\
\hline$c_{1}$ & $\begin{array}{l}-0.788 \\
(0.973)\end{array}$ & $0^{*}$ & $0^{*}$ \\
\hline \multicolumn{4}{|c|}{$\geq 49$ hours regime } \\
\hline$b_{2}$ & $\begin{array}{l}113.617 \\
(17.364)\end{array}$ & $\begin{array}{r}126.089 \\
(8.036)\end{array}$ & $\begin{array}{l}144.192 \\
(7.307) \\
\end{array}$ \\
\hline$c_{2}$ & $\begin{array}{l}-3.920 \\
(1.003)\end{array}$ & $\begin{array}{l}-4.533 \\
(0.657)\end{array}$ & $\begin{array}{l}-3.709 \\
(0.570)\end{array}$ \\
\hline \multicolumn{4}{|c|}{ both hours regimes } \\
\hline Sunday & & & $\begin{array}{l}-858.162 \\
(125.727) \\
\end{array}$ \\
\hline$H^{x \max }$ & 63 & 63 & 68 \\
\hline \multicolumn{4}{|c|}{ goodness of fit statistics } \\
\hline$R^{2}$ & 0.738 & 0.736 & 0.812 \\
\hline see & 592.16 & 591.28 & 500.98 \\
\hline
\end{tabular}

The asterisk denotes a constrained coefficient. 
Table 5

Least-Squares Estimates of Equation (5) $\ln \left(X_{t}\right)=\delta_{0}+\delta_{1} \ln \left(H_{t}\right)+u_{4 t}$ Fitted to all Observations, to Observations in the Shorter Hours Regime, and to Observations in the Longer Hours Regime

\begin{tabular}{|l|c|c|c|}
\hline & estimated coefficient (standard & \multicolumn{2}{|c|}{ goodness of fit statistics } \\
\cline { 3 - 4 } & error in parentheses) on $\ln \left(H_{t}\right)$ & $R^{2}$ & see \\
\hline all 122 observations & $0.794(0.048)$ & 0.725 & 0.110 \\
\hline observations for hours $<49$ & $1.002(0.087)$ & 0.778 & 0.120 \\
\hline observations for hours $\geq 49$ & $0.172(0.089)$ & 0.218 & 0.076 \\
\hline
\end{tabular}

Table 6

Descriptive Statistics on a Cross-Section of Individual Women Munition Workers

\begin{tabular}{|l|c|c|}
\hline & \multicolumn{2}{|c|}{ Women Munition Workers } \\
\hline & $\begin{array}{c}\text { hours worked per } \\
\text { week }\end{array}$ & $\begin{array}{c}\text { shells produced } \\
\text { per week }\end{array}$ \\
\hline number of observations & & 33 \\
\hline mean, $\mu$ & 44.8 & 375.3 \\
\hline median, $M$ & 38.0 & 355.0 \\
\hline first quartile, $Q_{1}$ & 32.5 & 298 \\
\hline third quartile, $Q_{3}$ & 58.0 & 193.0 \\
\hline minimum & 25.0 & 544.0 \\
\hline maximum & 63.0 & 94.92 \\
\hline standard deviation, $\sigma$ & 11.83 & 0.253 \\
\hline coefficient of variation, $\sigma / \mu$ & 0.264 & 0.254 \\
\hline$\left[1 / 2\left(Q_{3}-Q_{\nu}\right)\right] \div M$ & 0.336 & \\
\hline
\end{tabular}


Table 7

Least-Squares Estimates of the Slope Coefficients (and Estimated Standard Errors in Parentheses) of Output-Hours Equations Fitted to Observations on 43 Women Engaged in “the hardest in shell-making”.

\begin{tabular}{|c|c|c|c|c|}
\hline \multirow{4}{*}{$\begin{array}{l}\text { RHS } \\
\text { variable }\end{array}$} & \multicolumn{4}{|c|}{ dependent variable is........................ } \\
\hline & $\ldots . X_{i}$ & $\ldots X_{i}$ & $\ldots X_{i}$ & $\ldots . \ln \left(X_{i}\right)$ \\
\hline & equation (1) & equation (2) & equation (3) & equation (5) \\
\hline & \multicolumn{4}{|c|}{$\begin{array}{l}\text { estimated coefficients (and estimated standard errors in } \\
\text { parentheses) attached to variables listed in the first column }\end{array}$} \\
\hline$H_{i}$ & $\begin{array}{r}7.374 \\
(0.494)\end{array}$ & $\begin{array}{l}12.406 \\
(5.852)\end{array}$ & $\begin{array}{r}69.742 \\
(31.684)\end{array}$ & \\
\hline$H_{i}{ }^{2}$ & & $\begin{array}{l}-0.055 \\
(0.063)\end{array}$ & $\begin{array}{l}-1.385 \\
(0.726)\end{array}$ & \\
\hline$H_{i}{ }^{3}$ & & & $\begin{array}{c}0.010 \\
(0.005)\end{array}$ & \\
\hline $\ln \left(H_{i}\right)$ & & & & $\begin{array}{c}0.898 \\
(0.057)\end{array}$ \\
\hline$H^{x \max }$ & ND & beyond ob & erved hours & ND \\
\hline \multicolumn{5}{|c|}{ goodness of fit statistics } \\
\hline $\mathrm{R}^{2}$ & 0.845 & 0.847 & 0.860 & 0.852 \\
\hline see & 37.879 & 37.998 & 36.914 & 0.099 \\
\hline
\end{tabular}

see is the standard error of estimate of the equation and $H^{x m a x}$ is the hours of work at which output reaches a maximum as implied by the point estimates of the fitted equation. The forms of equations (1) and (5) do not permit such a stationary value and ND means "not defined”. Estimates of equations (2) and (3) imply a maximum of output beyond those hours observed by these workers. 
Table 8

Descriptive Statistics on Hours Since Start of Work, Hourly Output, and Number of Workers

\begin{tabular}{|c|c|c|c|c|c|c|c|c|c|}
\hline \multirow{3}{*}{ nobs } & \multicolumn{3}{|c|}{ Day } & \multicolumn{3}{|c|}{ Night } & \multicolumn{3}{|c|}{ Day \& Night Pooled } \\
\hline & \multicolumn{3}{|c|}{33} & \multicolumn{3}{|c|}{44} & \multicolumn{3}{|c|}{77} \\
\hline & $\begin{array}{l}\text { hours } \\
\text { since } \\
\text { start }\end{array}$ & $\begin{array}{l}\text { hourly } \\
\text { output }\end{array}$ & $\begin{array}{c}\text { \# of } \\
\text { workers }\end{array}$ & $\begin{array}{l}\text { hours } \\
\text { since } \\
\text { start }\end{array}$ & $\begin{array}{l}\text { hourly } \\
\text { output }\end{array}$ & $\begin{array}{c}\text { \# of } \\
\text { workers }\end{array}$ & $\begin{array}{c}\text { hours } \\
\text { since } \\
\text { start }\end{array}$ & $\begin{array}{l}\text { hourly } \\
\text { output }\end{array}$ & $\begin{array}{c}\text { \# of } \\
\text { workers }\end{array}$ \\
\hline mean, $\mu$ & 5.73 & 198 & 27 & 5.77 & 229 & 30 & 5.75 & 216 & 29 \\
\hline median, $M$ & 6 & 201 & 31 & 6 & 235 & 31 & 6 & 229 & 31 \\
\hline $1^{\text {st }}$ quartile, $Q_{1}$ & 3 & 144 & 17 & 3 & 199 & 28 & 3 & 174 & 27 \\
\hline $3^{\text {rd }}$ quartile, $Q_{3}$ & 8.5 & 256 & 34 & 8.5 & 256 & 32 & 8.5 & 256 & 33 \\
\hline minimum & 1 & 112 & 14 & 1 & 134 & 20 & 1 & 112 & 14 \\
\hline maximum & 10.5 & 278 & 40 & 10.5 & 316 & 38 & 10.5 & 316 & 40 \\
\hline standard deviation, $\sigma$ & 3.0 & 54.7 & 8.8 & 3.0 & 45.8 & 4.4 & 3.0 & 51.8 & 6.8 \\
\hline$\sigma / \mu$ & 0.53 & 0.28 & 0.32 & 0.52 & 0.20 & 0.14 & 0.52 & 0.24 & 0.234 \\
\hline$\left[1 / 2\left(Q_{3}-Q_{1}\right)\right] \div M$ & 0.46 & 0.28 & 0.27 & 0.46 & 0.12 & 0.07 & 0.46 & 0.18 & 0.10 \\
\hline
\end{tabular}

“nobs” means number of hourly observations. 
Table 9

Least-Squares Estimates of Output of Shells per Hour Regressed on Hours Worked Since Starting Work and Other Variables: 77 Pooled Day and Night Observations

\begin{tabular}{|c|c|c|c|c|}
\hline \multirow{4}{*}{$\begin{array}{l}\text { RHS } \\
\text { variable }\end{array}$} & \multicolumn{4}{|c|}{ dependent variable is......................... } \\
\hline & $\ldots . x_{j}$ & $\ldots . x_{j}$ & $\ldots . x_{j}$ & $\ldots \cdot \ln \left(x_{j}\right)$ \\
\hline & equation (6) & equation (7) & equation (8) & equation (9) \\
\hline & \multicolumn{4}{|c|}{$\begin{array}{l}\text { estimated coefficients (and estimated standard errors in } \\
\text { parentheses) attached to variables listed in the first column }\end{array}$} \\
\hline \multirow[t]{2}{*}{$h_{j}$} & -3.893 & 12.991 & -10.294 & \\
\hline & $(1.128)$ & $(4.400)$ & $(12.821)$ & \\
\hline \multirow[t]{2}{*}{$h_{j}{ }^{2}$} & & -1.465 & 3.363 & \\
\hline & & $(0.371)$ & $(2.529)$ & \\
\hline \multirow[t]{2}{*}{$h_{j}{ }^{3}$} & & & -0.279 & \\
\hline & & & $(0.145)$ & \\
\hline \multirow[t]{2}{*}{$\ln \left(h_{j}\right)$} & & & & -0.060 \\
\hline & & & & $(0.024)$ \\
\hline$h^{D R}$ & 1 & 4.4 & 6 & 1 \\
\hline \multirow[t]{2}{*}{$L_{j}$} & 6.117 & 6.262 & 6.295 & 0.031 \\
\hline & $(0.558)$ & $(0.510)$ & $(0.501)$ & $(0.003)$ \\
\hline \multirow[t]{2}{*}{$K_{j}$} & 35.706 & 36.339 & 36.351 & 0.167 \\
\hline & $(7.343)$ & $(6.699)$ & $(6.574)$ & $(0.036)$ \\
\hline \multirow[t]{2}{*}{$N_{j}$} & 16.970 & 16.460 & 16.213 & 0.088 \\
\hline & $(6.818)$ & (6.219) & $(6.105)$ & $(0.033)$ \\
\hline \multicolumn{5}{|c|}{ goodness of fit statistics } \\
\hline$R^{2}$ & 0.711 & 0.763 & 0.775 & 0.720 \\
\hline see & 28.62 & 26.097 & 25.611 & 0.139 \\
\hline
\end{tabular}

see is the standard error of estimate of the equation. $h^{D R}$ denotes the hours since starting work when diminishing returns set in. 
Table 10

Least-Squares Estimates of Output of Shells per Hour Regressed on Hours Worked Since Starting Work and Other Variables: Fitted to Night and Day Observations Separately

\begin{tabular}{|c|c|c|c|c|c|c|c|c|}
\hline \multirow{5}{*}{$\begin{array}{l}\text { RHS } \\
\text { variable }\end{array}$} & \multicolumn{8}{|c|}{ dependent variable is.............................. } \\
\hline & \multicolumn{2}{|c|}{$\ldots x_{j}$} & \multicolumn{2}{|c|}{$\ldots . x_{j}$} & \multicolumn{2}{|c|}{$\ldots . x_{j}$} & \multicolumn{2}{|c|}{$\ldots \cdot \ln \left(x_{j}\right)$} \\
\hline & \multicolumn{2}{|c|}{ equation (6) } & \multicolumn{2}{|c|}{ equation (7) } & \multicolumn{2}{|c|}{ equation (8) } & \multicolumn{2}{|c|}{ equation (9) } \\
\hline & Day & Night & Day & Night & Day & Night & Day & Night \\
\hline & \multicolumn{8}{|c|}{$\begin{array}{l}\text { estimated coefficients (and estimated standard errors in parentheses) attached to } \\
\text { variables listed in the first column }\end{array}$} \\
\hline$h_{j}$ & $\begin{array}{l}-4.311 \\
(1.291)\end{array}$ & $\begin{array}{l}-3.662 \\
(1.747)\end{array}$ & $\begin{array}{l}11.278 \\
(4.604)\end{array}$ & $\begin{array}{l}13.947 \\
(7.063)\end{array}$ & $\begin{array}{c}1.982 \\
(13.633)\end{array}$ & $\begin{array}{l}-20.356 \\
(20.560)\end{array}$ & & \\
\hline$h_{j}{ }^{2}$ & & & $\begin{array}{l}-1.351 \\
(0.388)\end{array}$ & $\begin{array}{l}-1.528 \\
(0.596)\end{array}$ & $\begin{array}{c}0.580 \\
(2.691)\end{array}$ & $\begin{array}{c}5.570 \\
(4.051)\end{array}$ & & \\
\hline$h_{j}^{3}$ & & & & & $\begin{array}{l}-0.112 \\
(0.154)\end{array}$ & $\begin{array}{l}-0.410 \\
(0.232)\end{array}$ & & \\
\hline $\ln \left(h_{j}\right)$ & & & & & & & $\begin{array}{l}-0.058 \\
(0.031)\end{array}$ & $\begin{array}{r}-0.064 \\
(0.035)\end{array}$ \\
\hline$h^{D R}$ & 1 & 1 & 4 & 5 & 5 & 6 & 1 & 1 \\
\hline$L_{j}$ & $\begin{array}{c}6.147 \\
(0.557)\end{array}$ & $\begin{array}{c}5.587 \\
(1.197)\end{array}$ & $\begin{array}{c}6.225 \\
(0.491)\end{array}$ & $\begin{array}{r}5.920 \\
(1.129)\end{array}$ & $\begin{array}{c}6.248 \\
(0.496)\end{array}$ & $\begin{array}{c}5.900 \\
(1.099)\end{array}$ & $\begin{array}{c}0.033 \\
(0.003)\end{array}$ & $\begin{array}{c}0.027 \\
(0.006)\end{array}$ \\
\hline$K_{j}$ & $\begin{array}{c}31.910 \\
(10.258)\end{array}$ & $\begin{array}{c}37.837 \\
(10.306)\end{array}$ & $\begin{array}{l}32.453 \\
(8.718)\end{array}$ & $\begin{array}{l}38.261 \\
(9.658)\end{array}$ & $\begin{array}{l}32.553 \\
(8.794)\end{array}$ & $\begin{array}{l}38.237 \\
(9.404)\end{array}$ & $\begin{array}{c}0.165 \\
(0.058)\end{array}$ & $\begin{array}{c}0.175 \\
(0.048)\end{array}$ \\
\hline goodness & f fit statis & & & & & & & \\
\hline $\mathrm{R}^{2}$ & 0.867 & 0.492 & 0.908 & 0.565 & 0.909 & 0.598 & 0.843 & 0.497 \\
\hline see & 20.928 & 33.807 & 17.785 & 31.674 & 17.937 & 30.841 & 0.118 & 0.156 \\
\hline
\end{tabular}

see is the standard error of estimate of the equation and $h^{D R}$ denotes the hours since starting work when diminishing returns set in. 
Figure 1

Weekly Output and Weekly Hours: 56 Observations on One Hundred Women Turning Fuze Bodies and 26 Observations on Forty Women Milling a Screw Thread on Fuze Bodies

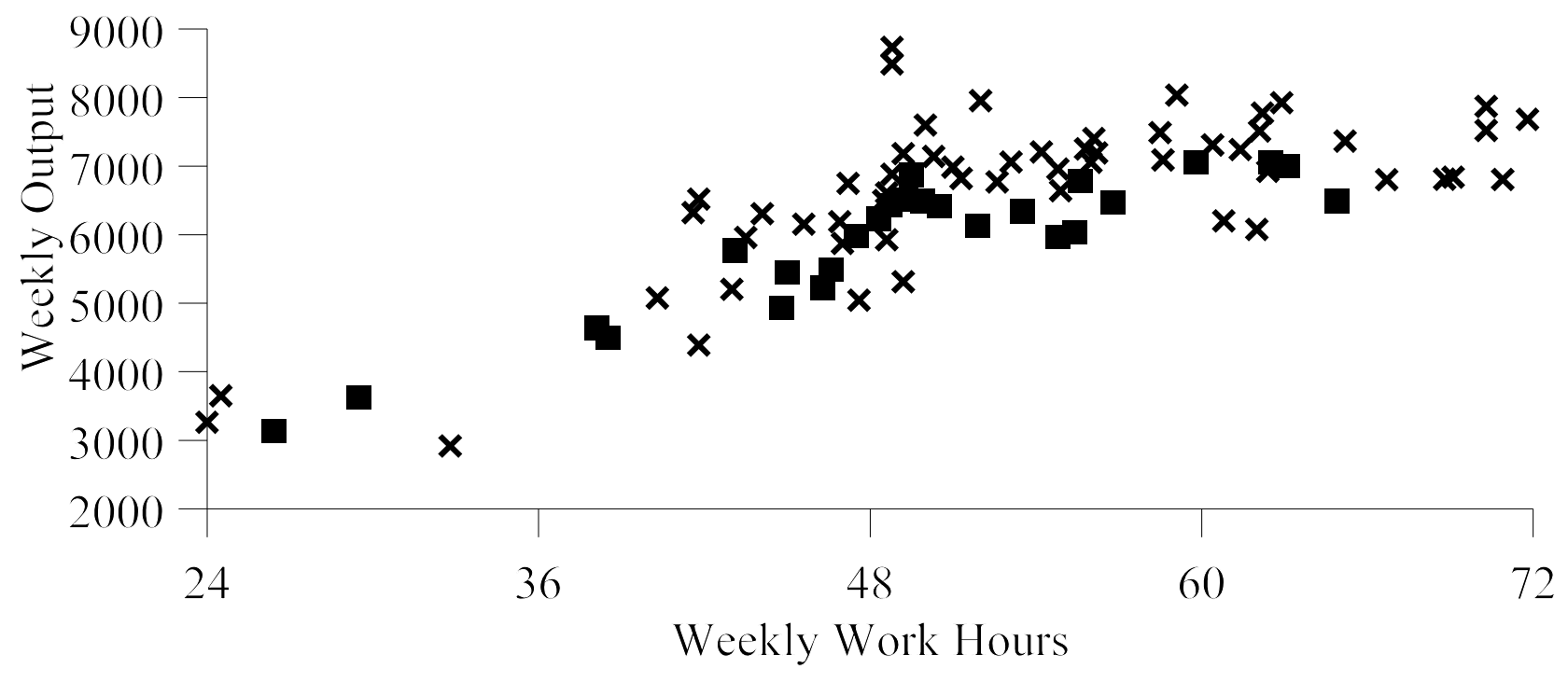

x $\quad 100$ Women Turning Fuze Bodies

- 40 Women Milling a Screw Thread 
Figure 2

Weekly Output and Weekly Hours: 31 Observations on Fifty-Six Men Sizing Fuze Bodies and 9 Observations on 15 Youths Boring Top Caps

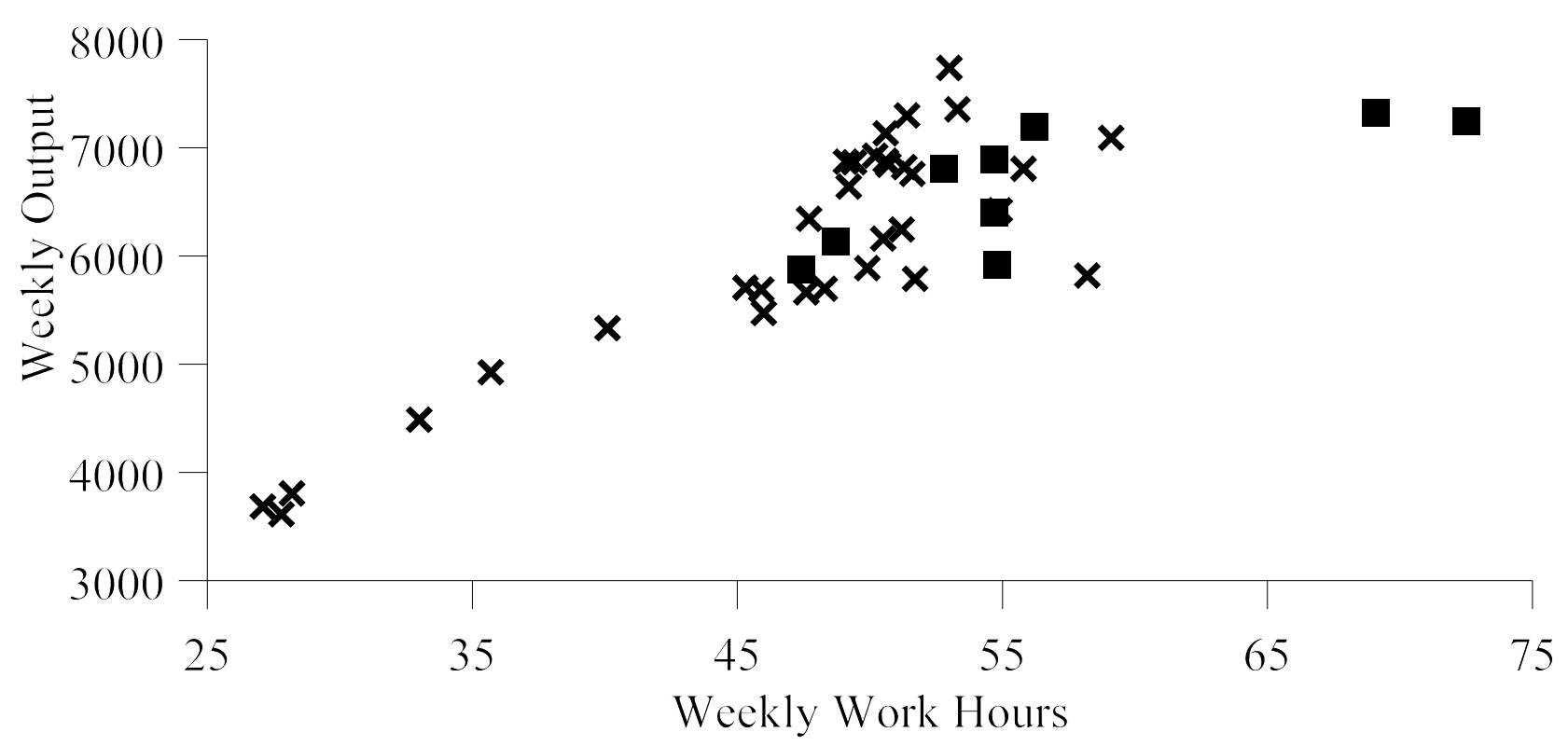

X Men Sizing Fuze Bodies - Y Youths Boring Top Caps 
Figure 3

Implied Output-Hours Relation Corresponding to Estimates of Equations (2) and (3) for the 122 Weekly Observations on All Workers
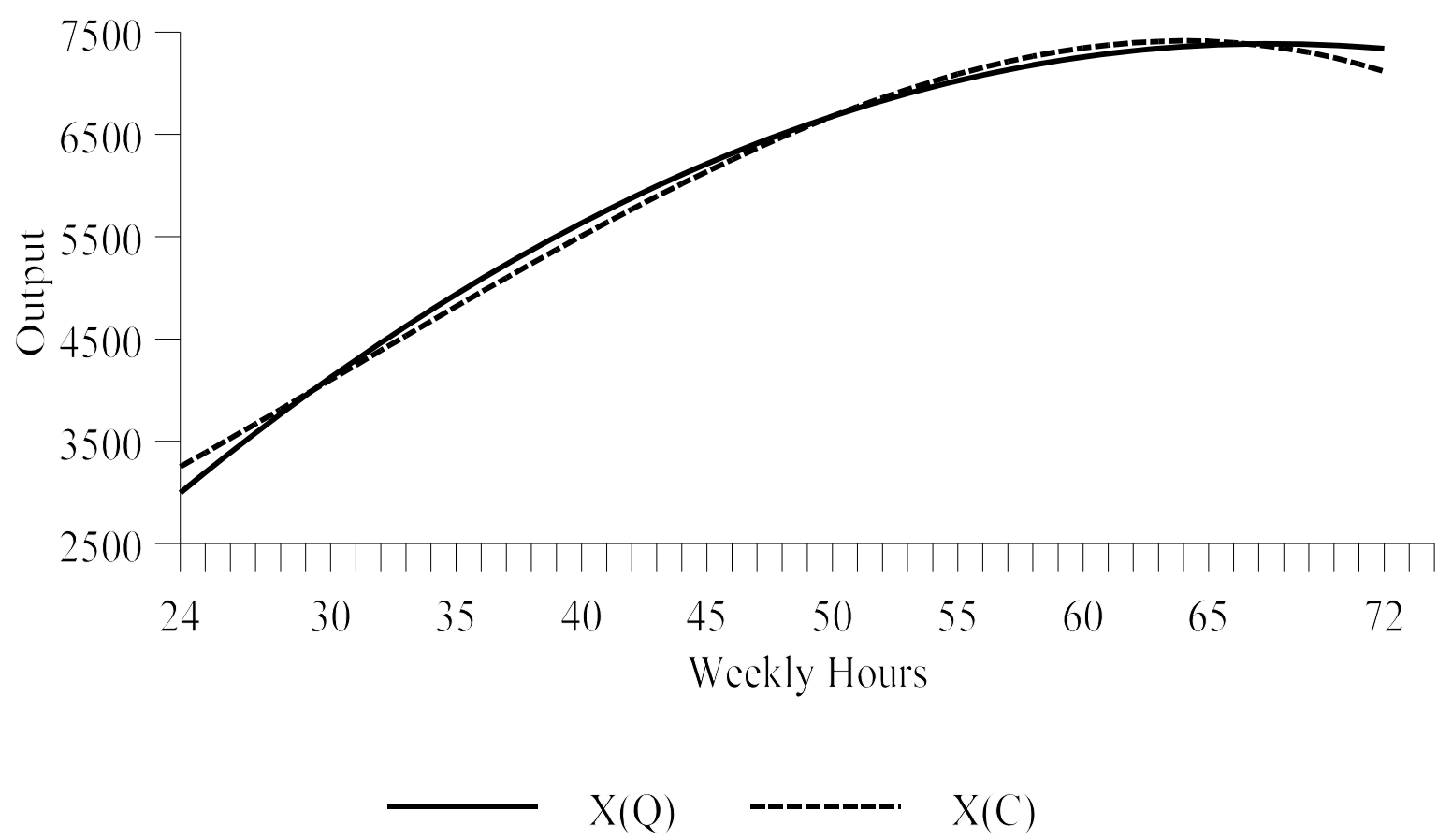

$\mathrm{X}(\mathrm{Q})$ denotes the output-hours relationship implied by the least-squares estimates of the equation in which hours are expressed as a quadratic (Q). X(C) denotes the output-hours relationship implied by the least-squares estimates of the equation in which hours are expressed as a cubic (C). 
Figure 4

Implied Output-Hours Relations Corresponding to Two Fitted Spline Functions

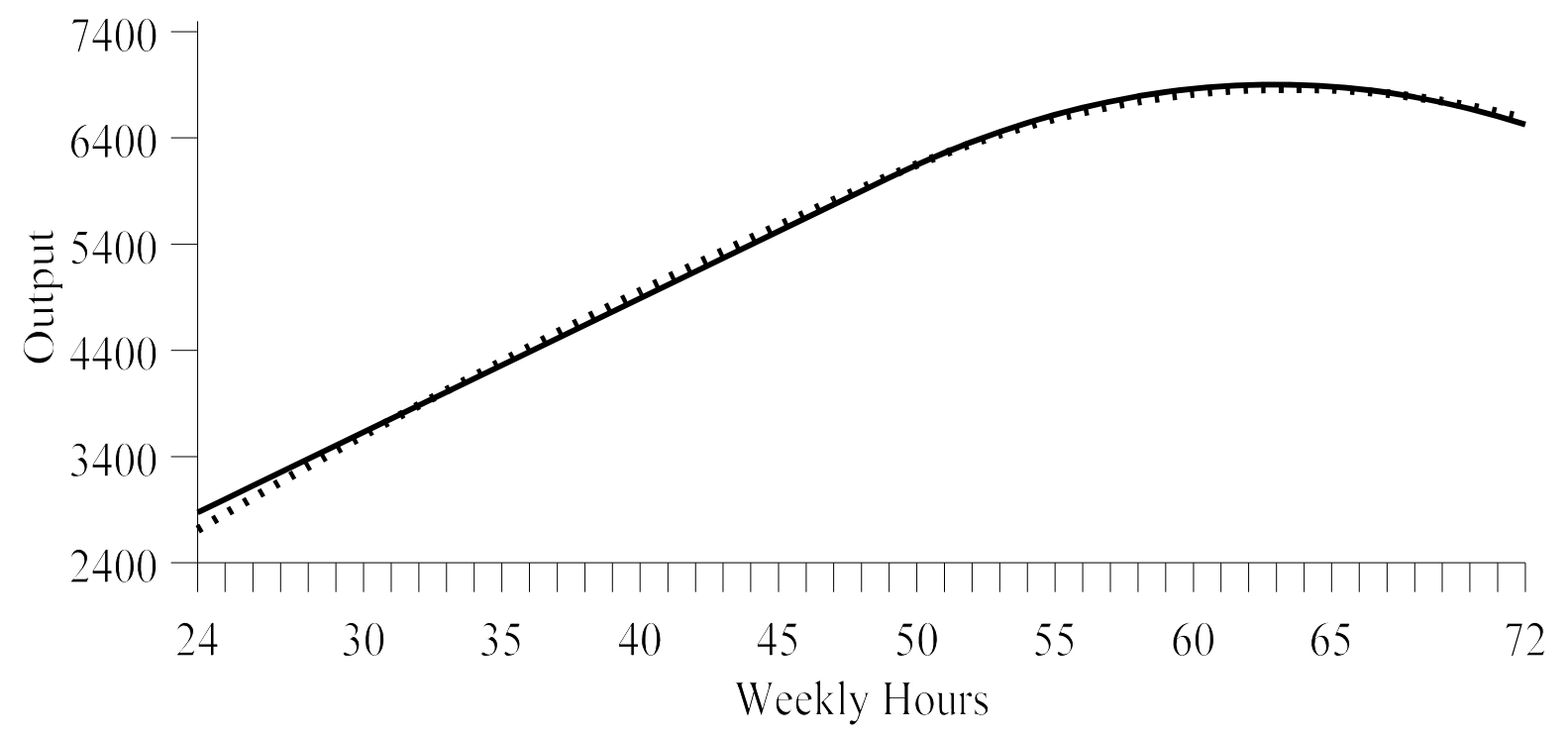

$\longrightarrow \mathrm{X}(\mathrm{L}-\mathrm{QS}) \quad \cdots \cdots \cdots \cdot \mathrm{X}(\mathrm{Q} \mathrm{S})$

$\mathrm{X}(\mathrm{QS})$ is the implied output-hours relationship fitted to all 122 weekly observations by a spline in which observations at less than 49 hours are described by a quadratic-in-hours function that meets smoothly a quadratic-in-hours function fitted to observations at 49 hours and above

$\mathrm{X}(\mathrm{L}-\mathrm{QS})$ is the implied output-hours relationship fitted to all 122 weekly observations by a spline in which observations at less than 49 hours are described by a linear-in-hours function that meets smoothly a quadratic-in-hours function fitted to observations at 49 hours and above.

Both equations are estimated with each group of workers having its own intercept. 


\section{Figure 5}

Marginal Product of Hours and Average Product of Hours Implied by the Estimates in column (ii) of Table 5 .

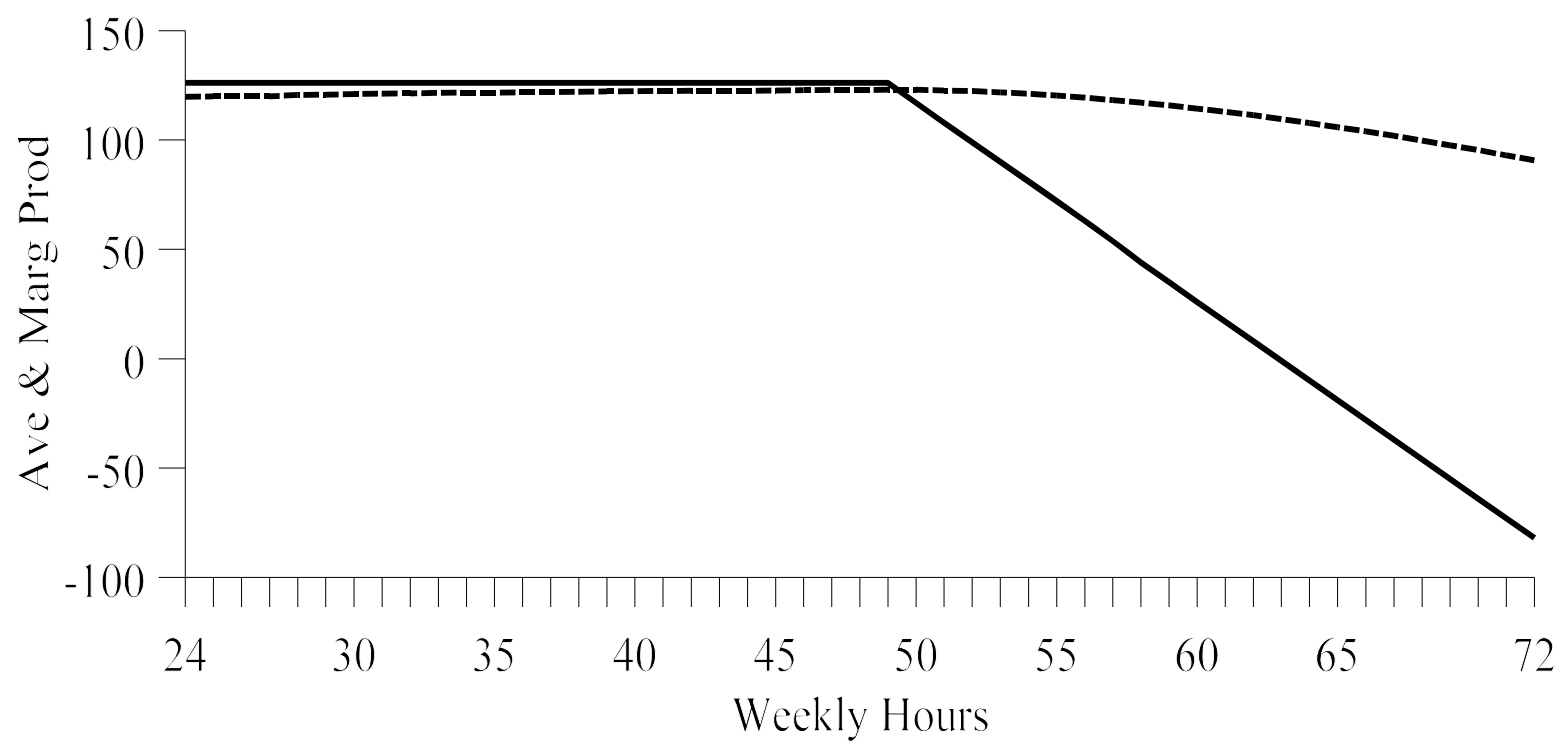

MPH is the marginal product of weekly hours and APH is the average product of weekly hours as implied by the output-hours equation whose estimates are reported in column (ii) of Table 5. This is a spline where a linear-in-hours equation is fitted to observations where hours are less than 49 hours and a quadratic-in-hours function is fitted to observations where hours are 49 and above. 
Figure 6

Implied Output-Hours Relation for 43 Women
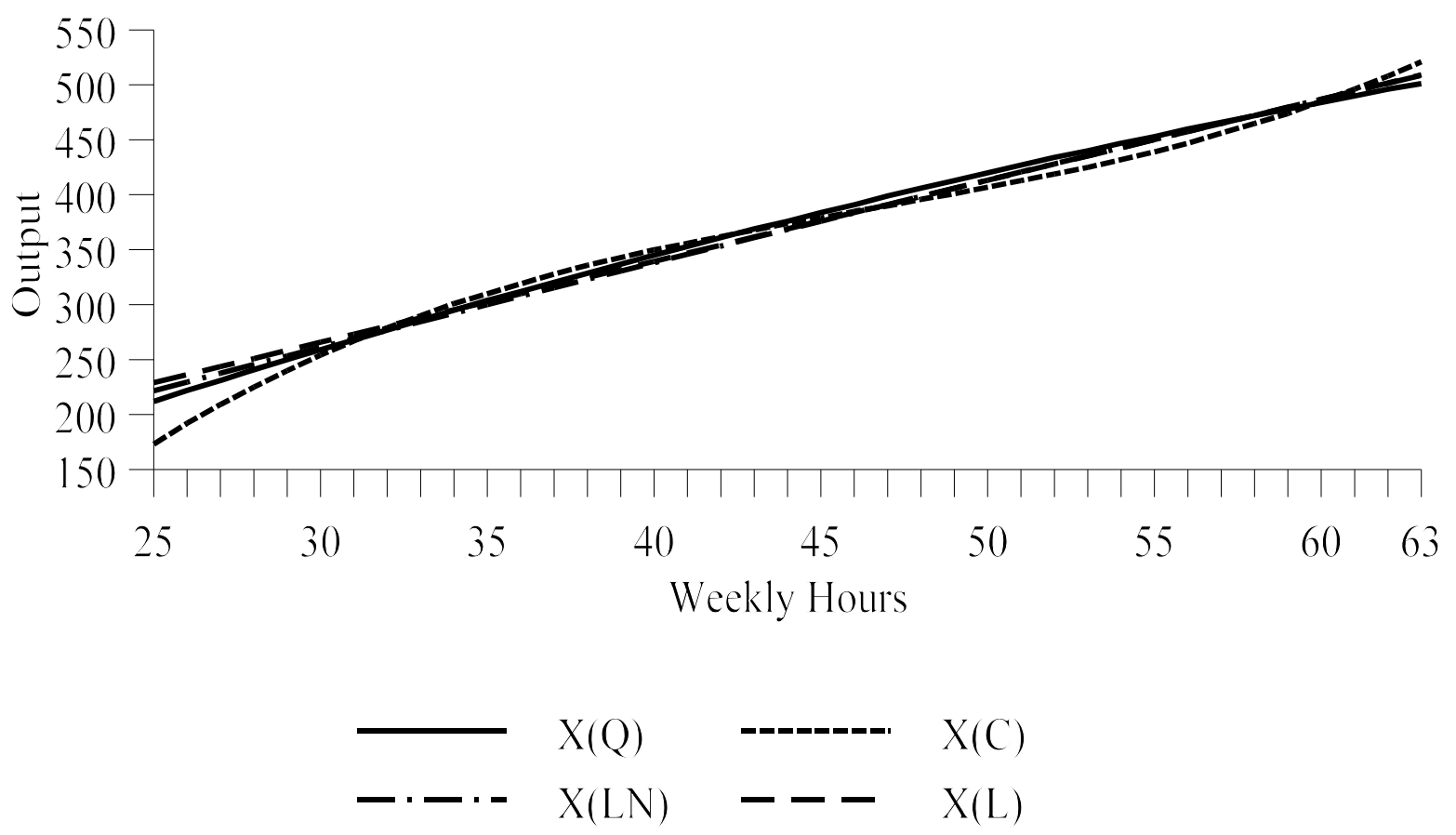

$\mathrm{X}(\mathrm{L})$ is the output-hours relationship implied by the least-squares estimates of the equation in which hours enters linearly. $\mathrm{X}(\mathrm{Q})$ denotes the output-hours relationship implied by the least-squares estimates of the equation in which hours are expressed as a quadratic (Q). $\mathrm{X}(\mathrm{C})$ denotes the output-hours relationship implied by the least-squares estimates of the equation in which hours are expressed as a cubic (C). X(LN) denotes the output-hours relationship implied by the log-linear (LN) specification. 


\section{Figure 7}

Simulations of Weekly Output for 43 Women:

Linear Output-Hours Equations Fitted to Night and Day Observations Separately

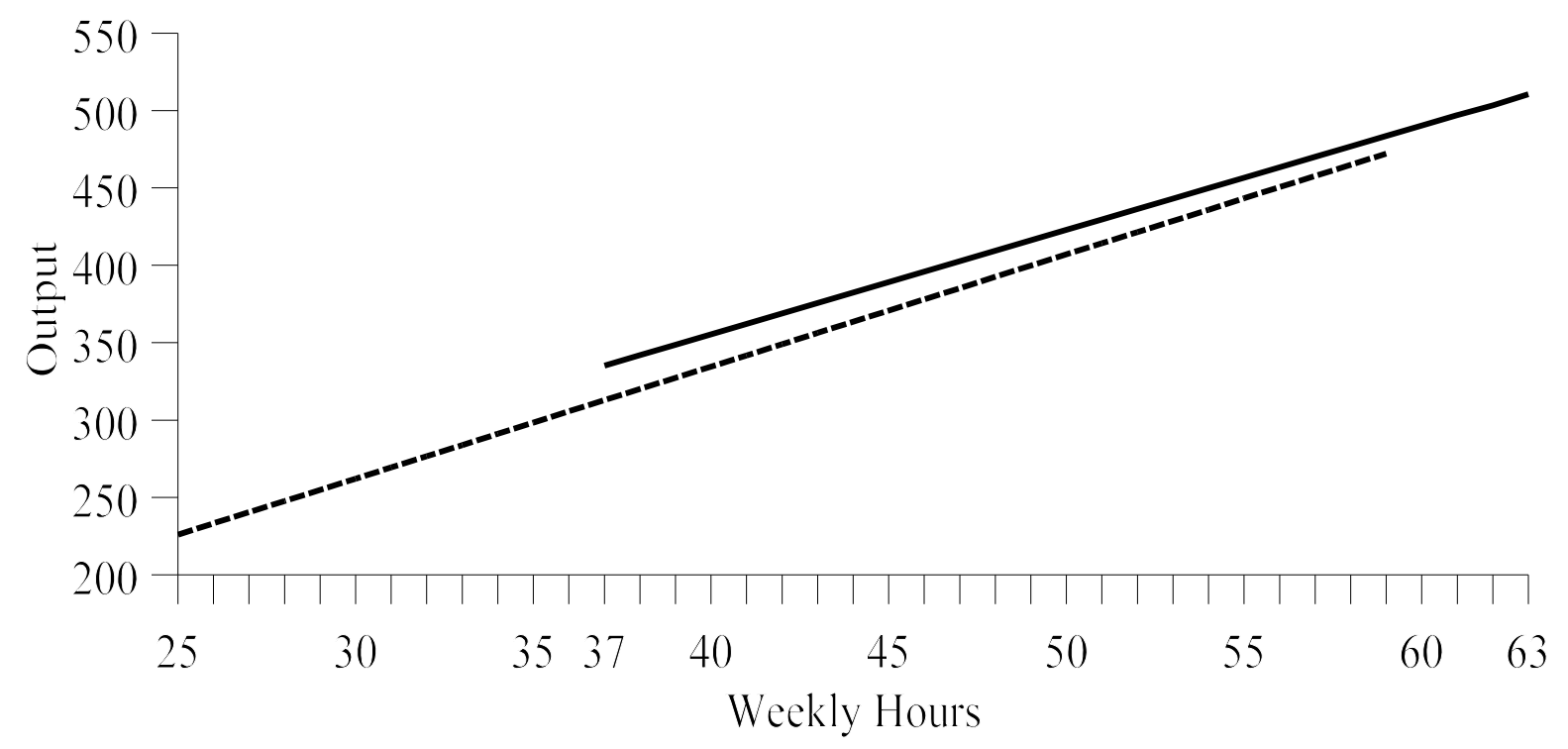

$\longrightarrow \quad \mathrm{X}(\mathrm{L})$-Night $\quad$------- X(L)-Day

Among Day workers, the shortest working week observed is 25 hours and the longest working week is 59 hours. Among Night workers, the shortest working week observed is 37 hours and the longest working week is 63 hours. $\mathrm{X}(\mathrm{L})$ is the output-hours relationship implied by the least-squares estimates of the equation in which hours enters linearly. 
Figure 8

Simulating the Least-Squares Estimates of the Relation between the Output Produced Each Hour over a Day or Night as Hours since Starting Work Increase: Implications of Four Equations Fitted to Day and Night Observations Pooled
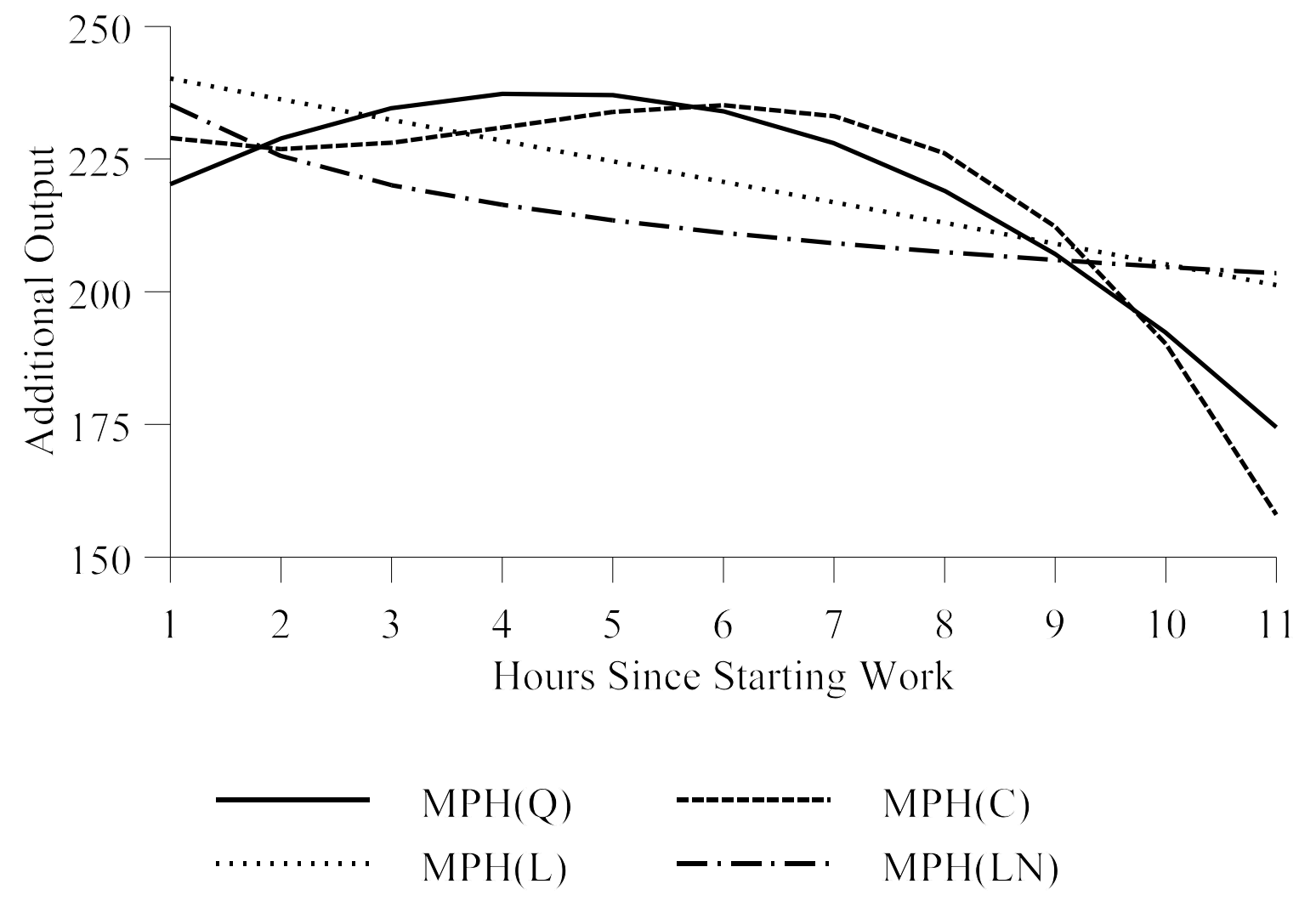

$\mathrm{MPH}(\mathrm{Q})$ is the marginal product of an hour since starting work as implied by the estimated quadraticin-hours equation. $\mathrm{MPH}(\mathrm{L})$ is the marginal product of an hour since starting work as implied by the estimated linear-in-hours equation. $\mathrm{MPH}(\mathrm{C})$ is the marginal product of an hour since starting work as implied by the estimated cubic-in-hours equation. MPH(LN) is the marginal product of an hour since starting work as implied by the estimated linear-in-logarithms equation. In simulating the marginal products from the fitted equations, in all cases, employment is set to its mean value of 29 workers and the machinery variable is set to the newer vintage $(K=1)$. 
Figure 9

Simulating the Least-Squares Estimates of the Relation between the Output Produced Each Hour over a Day or Night as Hours since Starting Work Increase: Implications of Quadratic-in-Hours Equations Fitted to Day and Night Observations Separately
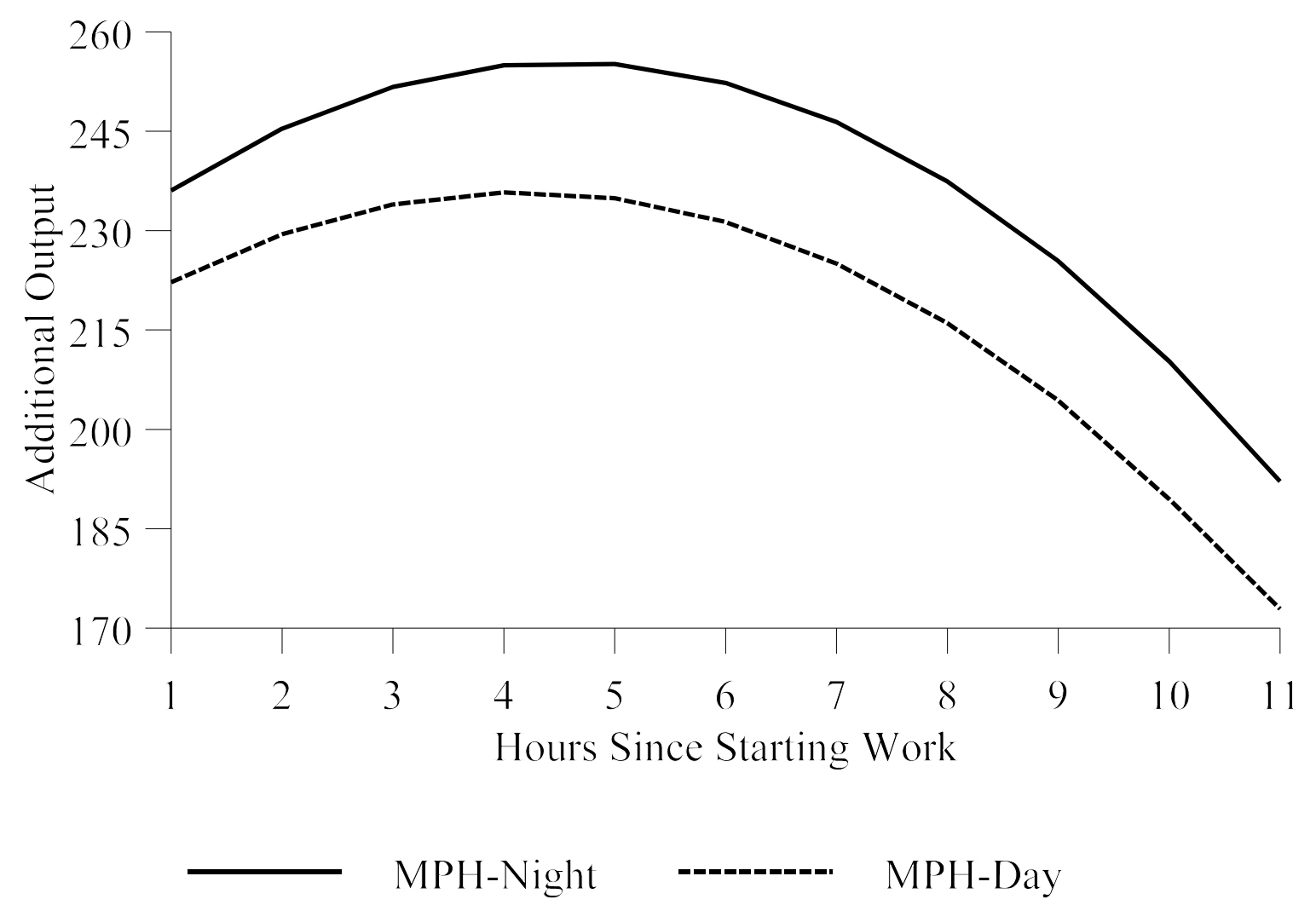

\section{MPH-Day}

MPH-Night is the marginal product of an hour since starting work as implied by the estimated quadratic-in-hours equation fitted to the observations on the night shifts. MPH-Day is the marginal product of an hour since starting work as implied by the estimated quadratic-in-hours equation fitted to the observations on the day shifts. In simulating the marginal products from the fitted equations, in both cases, employment is set to its overall mean value of 29 workers and the machinery variable is set to the newer vintage $(K=1)$. 
Figure 10

Average Weekly Hours and Average Real Hourly Compensation of Production Workers in

Manufacturing, 1890-2006

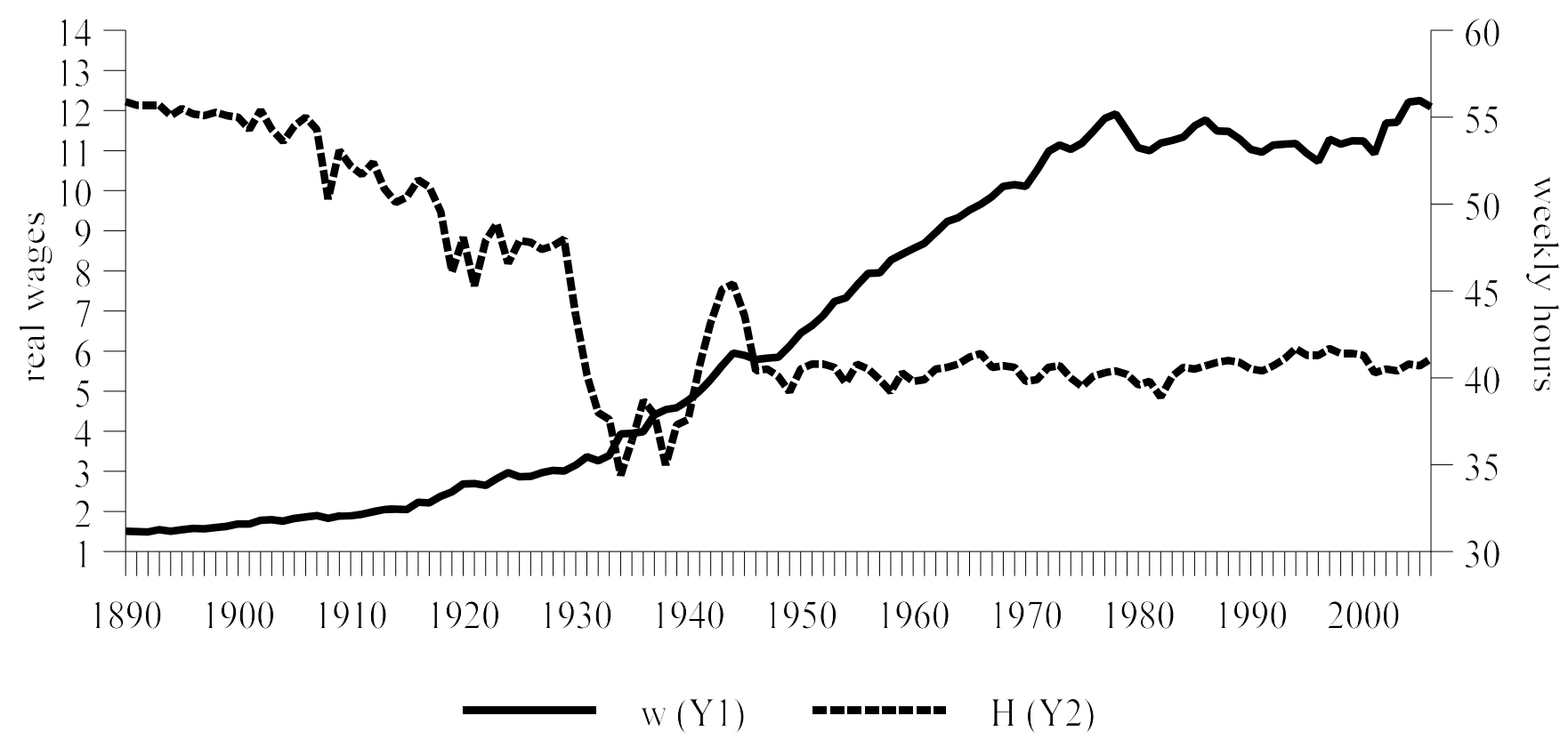

Notes to Figure 10.

In the Figure, $w$ (measured on the left-hand axis) denotes real average hourly compensation in dollars per hour in manufacturing industry (where the price deflator is a consumer price index with base in 1982-84) and $H$ is average weekly hours worked (measured on the right-hand axis). The series on $w$ is from Officer (2009, Table 7.7, p. 170). For the years 1900 to 1938, the average weekly hours worked in manufacturing are from Jones (1963) and, from 1939, weekly hours are contained in the Bureau of Labor Statistics Current Employment Statistics national survey series of about 490,000 workplaces: http://www.bls.gov/ces/. Between 1890 and 1899 the hours series is taken from series D-765 in the Historical Statistics of the United States. This series is believed to overstate hours of work. Therefore, using the 1900 figure of 59 hours for series D-765 and Jones' figure for 1900 of 55 hours, the hours figures for each year from 1890 to 1899 were adjusted downwards by 0.932 (which is 55/59). 
Figure 11

Lewis’ Framework for the Identification of a Labor Supply Function

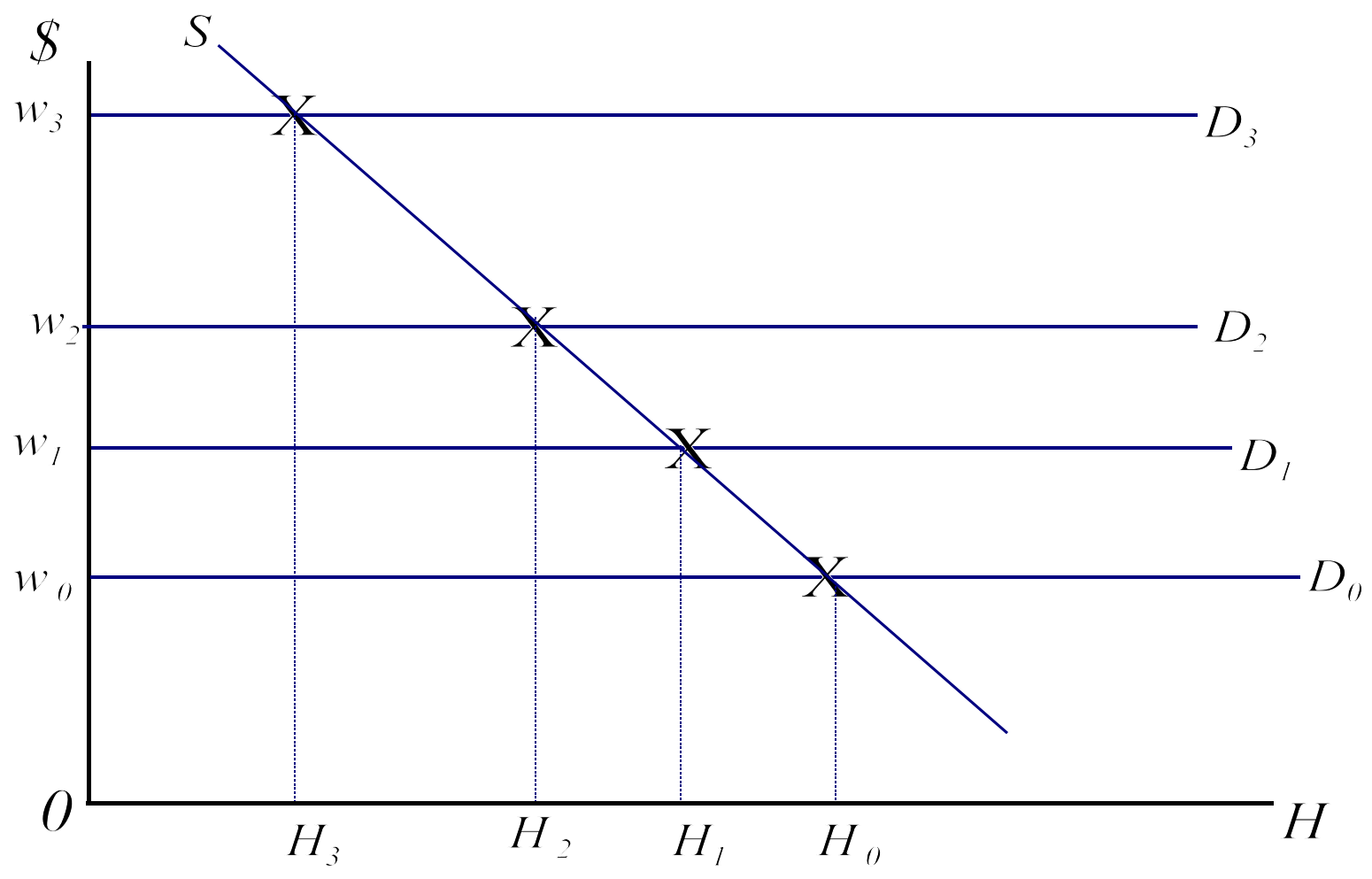

Notes to Figure 11

In the graph above, the $\mathbf{X}$ combinations of real wages and work hours trace out the effect of a horizontal labor (hours of work) demand function rising over time $\left(D_{0}, D_{1}, D_{2}, D_{3}\right.$ above) and an unchanged negatively-sloped labor (hours of work) supply function (given by $S$ in the figure). Over time, higher real wages $\left(w_{0}, w_{1}, w_{2}, w_{3}\right.$ above) are associated with shorter hours of work $\left(H_{0}, H_{1}, H_{2}, H_{3}\right)$. Real wages are determined by the location of the (assumed horizontal) demand function and working hours are determined by the worker's preferences embodied in the supply function. 
Figure 12

An Alternative Explanation for the Reduction in Working Hours from 1890 to 1920

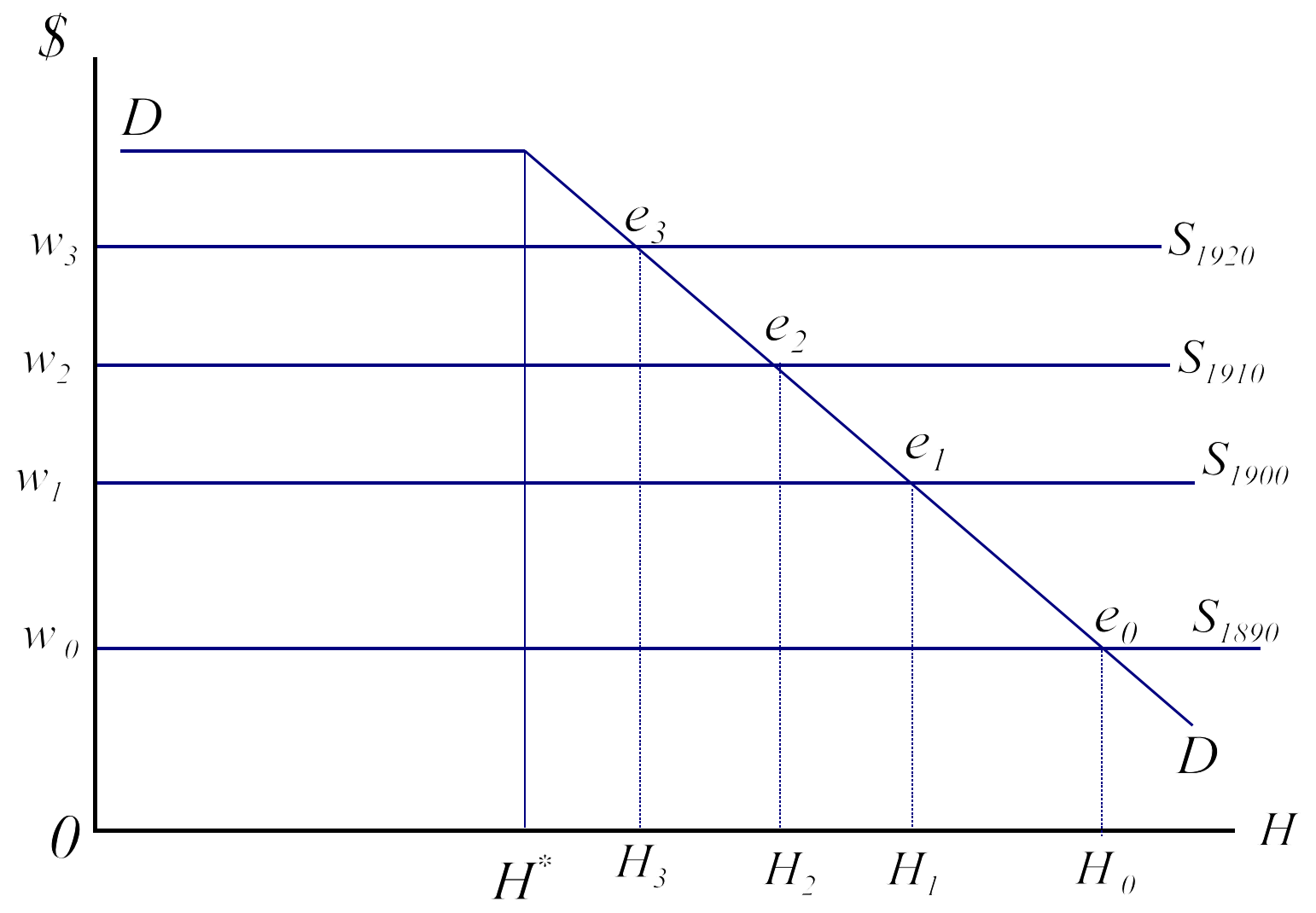

Notes to Figure 12

The demand curve for hours, $D D$, has a kink at $H^{*}$ hours: at hours less than $\mathrm{H}^{*}$, the employer is indifferent to the hours worked by an individual; at hours more than $\mathrm{H}^{*}$, the worker's marginal product falls as hours increase. In the region to the right of $H^{*}$, real wages are determined by the (assumed horizontal) supply function. The coordinates to $e_{0}, e_{1}, e_{2}, e_{3}$ trace the effect of a horizontal labor supply function rising over time (as $S_{1890}, S_{1900}, S_{1910}, S_{1920}$ ) and an unchanged kinked (hours of work) demand function given by $D D$. Over time, higher real wages are associated with shorter hours of work. 